OPEN ACCESS

Edited by:

Lino Nobili,

University of Genova, Italy

Reviewed by: Heinrich S. Gompf, University of Massachusetts Medical

School, United States

Gilles Vandewalle,

University of Liège, Belgium

*Correspondence: Mónica M. C. González mgonzalez@ifn.com.ar

Specialty section: This article was submitted to Sleep and Chronobiology, a section of the journal Frontiers in Neurology

Received: 06 April 2018

Accepted: 09 July 2018

Published: 02 August 2018

Citation: González MMC (2018) Dim Light at Night and Constant Darkness: Two

Frequently Used Lighting Conditions

That Jeopardize the Health and Well-being of Laboratory Rodents.

Front. Neurol. 9:609. doi: 10.3389/fneur.2018.00609

\section{Dim Light at Night and Constant Darkness: Two Frequently Used Lighting Conditions That Jeopardize the Health and Well-being of Laboratory Rodents}

\author{
Mónica M. C. González* \\ Sección Cronobiología y Sueño, Instituto Ferrero de Neurología y Sueño, Buenos Aires, Argentina
}

The influence of light on mammalian physiology and behavior is due to the entrainment of circadian rhythms complemented with a direct modulation of light that would be unlikely an outcome of circadian system. In mammals, physiological and behavioral circadian rhythms are regulated by the suprachiasmatic nucleus (SCN) of the hypothalamus. This central control allows organisms to predict and anticipate environmental change, as well as to coordinate different rhythmic modalities within an individual. In adult mammals, direct retinal projections to the SCN are responsible for resetting and synchronizing physiological and behavioral rhythms to the light-dark (LD) cycle. Apart from its circadian effects, light also has direct effects on certain biological functions in such a way that the participation of the SCN would not be fundamental for this network. The objective of this review is to increase awareness, within the scientific community and commercial providers, of the fact that laboratory rodents can experience a number of adverse health and welfare outcomes attributed to commonly-used lighting conditions in animal facilities during routine husbandry and scientific procedures, widely considered as "environmentally friendly." There is increasing evidence that exposure to dim light at night, as well as chronic constant darkness, challenges mammalian physiology and behavior resulting in disrupted circadian rhythms, neural death, a depressive-behavioral phenotype, cognitive impairment, and the deregulation of metabolic, physiological, and synaptic plasticity in both the short and long terms. The normal development and good health of laboratory rodents requires cyclical light entrainment, adapted to the solar cycle of day and night, with null light at night and safe illuminating qualities during the day. We therefore recommend increased awareness of the limited information available with regards to lighting conditions, and therefore that lighting protocols must be taken into consideration when designing experiments and duly highlighted in scientific papers. This practice will help to ensure the welfare of laboratory animals and increase the likelihood of producing reliable and reproducible results.

Keywords: lighting conditions, constant darkness, nightly dim light, laboratory rodents, circadian rhythms, suprachiasmatic nucleus, free running, health 


\section{INTRODUCTION}

In mammals, light is sensed by three types of retinal cells (photoreceptors): the outer rods/cones and the inner ganglion cells. Through a visual pathway, rods and cones regulate vision and allow representation of the environment; rods are responsible for vision at low light levels (scotopic-night vision) while cones are active at higher light levels (photopic-day vision) and capable of color vision. In addition, based on the level of light intensity and schedule of exposure, light exerts profound effects on physiology and behavior. This "non-image forming" function of light contributes to the behavioral and physiological responses that occur to environmental lighting conditions via the hypothalamic suprachiasmatic nucleus (SCN), the brain's master circadian clock, and a direct pathway that is not supposed to include the circadian system (1-25).

Most physiological and behavioral functions of vertebrates exhibit a diurnal rhythm which is generated by the bilateral SCN. This rhythm exhibits self-sustained oscillations at regular intervals of $\sim 24 \mathrm{~h}$ (circadian period; circa diem: near 1 day) in electrical activity, glucose utilization and gene expression $(9,11,16,26,27)$. Its molecular machinery lies in individual pacemaker neurons, and their single-cell rhythmicity is driven by an intrinsic molecular transcription/translation oscillation loop in which protein products regulate the expression of "clock" genes (including the period genes Per1 and Per2, and the crypotochrome genes, Cry1 and Cry2) and the transcription factors Clock (Circadian Locomotor Output Cycles Kaput) and Bmal1 (Brain and Muscle ARNT-like 1) $(9,28,29)$. In addition to the SCN, there are central and peripheral tissues containing cells with self-sustaining circadian oscillations that control local time- and tissue-specific processes. These are known as "peripheral clocks" and include notably the olfactory bulb, neocortex, cerebellum, amygdala, caudate-putamen, nucleus accumbens, hippocampus, ventral tegmental area, dorsomedial hypothalamus (DMH) retina, heart, kidney, lung, gastrointestinal tract, and liver $(4,30-32)$. The timing (phase and period) of these peripheral clocks is controlled by the SCN in order to maintain coherence among a wide array of behavioral and physiological circadian rhythms; this process is known as "internal synchronization" $(9,11,16,27,29,30,33,34)$.

Gene activation-deactivation in the circadian master-clock is reset daily by external time cues called zeitgebers ("time givers") that have the ability to adjust SCN clock mechanisms and overt circadian rhythms to environmental changes. The light-dark (LD) cycle is the most conspicuous zeitgeber for the circadian system and synchronizes the phase of endogenous rhythms with the appropriate daytime (light) and night (dark) phase; this process is known as "photoentrainment" $(4,7,9,14)$. The SCN predominantly entrains the circadian oscillations found in the hypothalamic-pituitary-adrenal (HPA) axis, the autonomic

Abbreviations: DD, long-term constant darkness; DMH, dorsomedial hypothalamus; SPV, subparaventricular zone; $\mathrm{DWL}_{\mathrm{N}}$, continuous dim white light at night; $\mathrm{DBL}_{\mathrm{N}}$, continuous dim blue light at night; $\mathrm{DRL}_{\mathrm{N}}$, continuous dim red light at night; DimRR, constant dim red light; LD, light-dark; mRGCs, melanopsin-containing ganglion cells; NA-LC, noradrenergic locus coeruleus; ROS, reactive oxygen species; SCN, suprachiasmatic nucleus. nervous system and neuronal systems to the LD cycle through the subparaventricular zone (SPV) and via relays in the DMH $(15,24,27,35-38)$.

In diurnal and nocturnal mammals, a subset of photosensitive inner retinal ganglion cells that express melanopsin (mRGCs) contribute to the non-visual response to light in collaboration with classical outer rods/cones photoreceptors. All these photoreceptors transform photic energy into an electrical signal (transduction) which passes to the brain in order to control circadian photoentrainment, locomotor activity, sleep, arousal, melatonin release, thermoregulation, heart rate, mood, cognitive functions, and pupillary light reflex $(1,4-7,10,12,13$, $17,19-22,25)$.

The retinal ganglion cells project to tens of brain regions and the mRGCS innervate most of them for integrating light responses and mediating photoentrainment of the circadian clock $(3,17,18,23)$. In agreement, the absence of mRGCs attenuates the phase resetting of light $(1,4,10,39-42)$. Photosensitivity is not uniform during the day. According to the time of day, light adjusts the spontaneous cycle of gene expression across the SCN to the day-night cycle, thus causing the phase shifts necessary for daily photoentrainment $(2,4,9$, $11,16,18)$. The most important time cues for resetting the principal circadian clock are the transitions between light and dark: light delays the phase of the endogenous rhythms over most of the night period while induces phase advances in the late night/early morning $(4,16,43)$. For example, brief pulses of light at night have the ability to drop body temperature facilitating EEG sleep ("photosomnolence") in mice $(39,44,45)$. This drop in core temperature would itself modulate other responses to light mediated via mRGCs-SCN, ultimately resulting in phase shifts (44). Furthermore, an acute dark pulse given during the light period triggers an alerting response through mRGCs $(39,45)$. Indeed, when the period of SCN rhythms is shorter than the period of the environmental LD cycle, entrainment requires a small delay that can be accomplished by night light exposure. When the period of the SCN rhythm is longer than the period of the external light cycle, entrainment requires a phase advance that can be achieved by late night/early morning light exposure $(2,9)$. The resetting effect of light on peripheral clock expression and organ-specific output is thought to be transmitted via SCN control over hormonal pathways and autonomic innervation (46). For example, melatonin is a neurohormone synthesized and secreted by the pineal gland; secretion is facilitated during darkness and the circadian rhythm is maintained and entrained by a multi-synaptic SCN-sympathetic pathway. Pineal melatonin levels provide a direct entrainment of the peripheral clock together with SCN feedback, further synchronizing circadian physiology over the entire organism (47-49).

The SCN presents two coupled, but anatomically and functionally distinct, oscillators: the ventrolateral (VL) SCN subdivision or "core," and the dorsomedial (DM) SCN, or "shell." The VL SCN receives the major input from the retina via the retinohypothalamic tract; clockwork mechanism and dependent rhythms are entrained by light and oscillate with a period equal to the external LD cycle. The DM SCN is not entrained by light and runs free in a manner which is independent of the 
lighting conditions with dependent rhythms which also free-run and oscillate with a period equal to the master self-sustaining circadian oscillation $(9,27,50,51)$. The DM area requires the VL SCN to maintain circadian rhythmicity and keep the related rhythms in synchrony with the LD cycle (2, 27, 51-56). Coupling and synchronization between the molecular circadian oscillators is mediated by neurotransmitters $(26,57)$. At the molecular level, light-induced resetting is primarily mediated by the rapid induction of the clock genes, mPer 1 and mPer2, in the VL SCN, which then spreads to the DM SCN. In particular, the early night delay phase induces mPer 1 and mPer2 initially in the VL SCN, which later induces mPer2 expression in the rhythmic cells of the DM SCN. In contrast, the late night advancing phase is only accompanied by mPer 1 gene expression in the VL SCN, which then spreads to the DM SCN without significant induction of mPer2 expression (2).

But how can SCN neurons manage to respond to light-dark transitions? The differing sensitivity of the retinal photopigments guarantees that the central clock will respond to irradiance and perceive the wavelength of transitions from twilight to daylight (blue-yellowish dark-light transitions) (58). The mRGCs are more sensitive to short wavelengths of light (blue light, $450-495 \mathrm{~nm})$ than green light $(495-570 \mathrm{~nm})$ and are practically insensitive to long wavelengths of light (red light, 620-750 nm). Instead, in the majority of rodents, rhodopsin-rod cells transduce low light intensities and exhibit peak sensitivity at $498 \mathrm{~nm}$ (blue-green light), while cones are sensitive under brighter conditions and express cone opsins that are maximally-sensitive at $360 \mathrm{~nm}$ (UV) and $508 \mathrm{~nm}$ (green) light (58). The mRGCs receive inputs from both rods and cones and modulates their activity $(17,21)$. Rod-phototransduction converges into mRGCS through two pathways, the rod bipolar pathway for circadian photoentrainment at low light intensities, and the rod-cone pathway for circadian photoentrainment at high light intensities (1). Cones use a direct pathway to the mRGCs for photoentrainment (59). In direct response to light, the mRGCs become depolarized and via the release of glutamate from the retinohypothalamic nerve terminals, activate the SCN lightsensitive pacemaker neurons $(25,50,51)$, although there are some differences in this mechanism across different species (60). Accordingly, blue light which represents the maximal sensitivity of the mRGCs, evokes the highest expression of Fos, Per 1, and Per2 in the SCN (20).

By having their physiological and behavioral rhythms in phase, and coordinated with environmental lighting conditions, individuals have the capacity to make the homeostatic adjustments necessary for their adaptation throughout the day. The whole system is in harmony with environmental demands and is able to respond in a manner suited to a changing and predictable milieu. Light is the strongest environmental influence on circadian timing and altering the LD cycle from the solar cycle of day and night affects the integrity of the circadian system and the SCN-dependent rhythms start to run in a misaligned manner, both between each other and with respect to the LD cycle. This is known as "internal desynchronization" and has serious consequences for the brain and body in both the short and long term $(11,14,34,61-68)$.
Apart from the SCN, light may also regulate certain mammalian biological functions through circuits directly influenced by mRGCs, which include pretectal olivary nuclei, SPV, lateral geniculate nucleus of the thalamus (the ventral division and the intergeniculate leaflet), medial amygdala, lateral habenula, ventral preoptic area, and lateral hypothalamus. These are implicated in the effect of light on circadian entrainment and the modulation of sleep, mood, and cognitive functions and pupillary light reflex, crude vision, glare, heart rate, and cortisol levels $(3,4,8,13,14,18,20,21,23,69,70)$.

It is assumed that experimental animals are raised and housed under strict and controlled standard lighting conditions as outlined in the Guide for the Care and Use of Laboratory Animals, which is published in a number of different countries. Nevertheless, certain lighting conditions, which have potentially long-lasting adverse outcomes on the welfare of laboratory animals, are often used in holding rooms and during tasks by animal care personnel and indeed, by some researchers.

The purpose of this review is to emphasize the need to avoid certain inadvertent or frequently used artificial lighting conditions on diurnal and nocturnal laboratory animals that challenge the appropriate development and function of the circadian system and other non-circadian brain areas. These artificial lighting conditions can impair the nervous system and alter physiological and behavioral processes in both the short and long term, thus invalidating experimental outcomes.

\section{WHICH LIGHTING CONDITIONS SHOULD WE BE AWARE OF? IDENTIFYING THE RISKS}

Time of day and the wavelength/intensity of the photic stimulus are variables that we should take careful control of because of their capacity to directly affect biological functions and shift the master clock and/or modulate photic synchronization $(20,71)$. Even a brief light pulse at night elicits circadian rhythm phase shifts $(18,19,71)$.

In mammals (including humans), the relevance of lighting conditions on health/disease begins as early as the intrauterine period, in which the circadian integrity of the mother is a key factor in conveying key environmental information related to time. During development, the fetal SCN is predominantly synchronized to the LD cycle by maternal hormonal signals and becomes vulnerable to environmental insults incurred by the mother (72-77). Once born, and until the SCN acquires its full functional capability ( $\sim 3$ weeks in rodents) (78-80), developing photoreceptors in the neonatal pineal organ, which will subsequently develop into typical secretory pinealocytes in adult (81), directly transmits information relating to environmental light conditions and collaborate with maternal cues in the regulation of biochemical rhythms during the first few days postnatally $(79,82)$. Thereafter, maternal entrainment declines and the development of a retina-SCN connection facilitates that this form of entrainment begins to be replaced by environmental cues such as the light-dark cycle for the photoentrainment of rhythms in the newborn $(73,74)$. As a direct consequence, 
the manipulation of gestational or postnatal photoperiods can influence the normal development and performance of the SCN, thus exerting influence over the outcome of circadian rhythms in both the short and long term (please refer to the following sections).

Most of us live under daily lighting schemes that do not follow the natural LD cycle in terms of schedule or the duration, wavelength and intensity of light, thus challenging our circadian system. In the evening, we are exposed for hours to incandescent bulb- and blue-enriched light from televisions, cell phones, and computer screens. Morning light has beneficial effects but at night can suppress melatonin concentrations, delay the onset of sleep by increasing alertness, decreases the efficiency of sleep at night and can reduce cognitive performance the next morning $(8,67,83-90)$. According to the maximal sensitivity of the mRGCs, blue light evokes the maximal magnitude of the phase-shift for human alertness, thermophysiology and heart rate (6). Misalignment of our internal timing with socially imposed environmental lighting conditions ("social jetlag") weakens synchronism between circadian rhythms and can exert dramatic effects upon physiology and behavior. Office workers and subway drivers that remain in dimly-lit environments for most of the day, along with frequent trans-meridian flyers and workers without a standard daytime schedule, are exposed to significant shifts in lighting cycles. As a result, irregular rhythms can emerge, which increase the risk of chronic health conditions such as sleep and mood disorders, cardiovascular and autoimmune diseases, cancer, obesity, stress, diabetes, premature aging, increased preterm births, spontaneous abortion, and lower birth weight (11, 63, 67, 68, 88, 89, 91-96).

Ordinarily, we would not even consider that such events could happen in animal housing facilities or experimental settings, since these animals must surely be held under safe and controlled lighting conditions. However, by lack of commitment or knowledge, the exposure of laboratory animals to aberrant lighting conditions is unexpectedly frequent.

\section{Lighting Conditions in Holding Rooms}

Since light represents the main environmental factor involved in the synchronization of biological rhythms and directly modulates sleep, mood and cognition, the consequences in terms of health and quality of life clearly depend on a regular LD cycle in agreement with local time, including sufficient light exposure time with adequate wavelength range and intensity during the day, and complete darkness at night. Based on scientific studies, worldwide guidelines for the management of environmental conditions recommend a semi-natural light cycle of 12:12 or 10:14 h with lighting within cages during the light phase below the threshold of aversion for mice/rats. For most pigmented strains, the recommended light level is below 60 lux, and for albino strains this is set to below $20-25 \operatorname{lux}\left[(97)^{1,2}\right.$, reviewed by $(98,99)]$.

\footnotetext{
${ }^{1}$ ARRP Guideline 22: Guidelines for the Housing of Mice in Scientific Institutions Animal Welfare Unit, NSW Department of Primary Industries, Australia.

${ }^{2}$ European convention for the protection of vertebrate animals used for experimental and other scientific purposes - Appendix A, Council of Europe Convention ETS 123.
}

Nevertheless, certain properties of light, such as intensity, wavelength range and distribution, are not clearly regulated by the Institutional Animal Care and Use Committee and are therefore frequently dismissed by providers and researchers. It is very common to find that rodents in holding rooms are exposed to different light intensities according to their location in the cage rack. Animals housed at the top of a rack are exposed, at the front of the cage, to more than 500 lux (up to 900 lux) while those at the bottom of the rack, nearest to the floor, can be exposed to 6 lux or less $(97,99)^{1}$, personal observation and personal communication with USA providers]. High light levels can dramatically affect retinal morphology and biochemistry. Consequently, rodents exposed to 130-270 lux above the light intensity under which they were raised are at risk of retinal damage $(97,102-104)^{1}$. A survey of Contract Research Organizations (CROs) located in North America, Europe, and Asia, using similar 12:12 lighting conditions, reported a high incidence of light-dependent retinopathy at a mean range of $210-490$ lux in albinos (99). Susceptibility is likely to be greater for older animals (105), and in both young and old animals undergoing certain treatments that cause pupillary dilation (e.g., clonidine) (106) or exert direct effects on photoreceptors (107); this susceptibility can be dependent upon both strain $(99,105$, $108,109)$ and previous light-history $(98,109-113)$. Moreover, animals that are exposed for long periods to low lighting conditions are more susceptible to retinal damage in response to light (98) ${ }^{1}$. Thus, placing animals housed in the bottom of a rack on to shelves in the upper part of a rack is not recommended. Light-induced retinal damage is likely to cause differences in biological rhythm parameters between animals and thus lead to significant variation in experimental results. There is no information available (either published or via the manufacturers) relating to the light properties inside the newest ventilated cages; this represents an important gap in our knowledge.

To guarantee the accuracy and integrity of future research, laboratory animals should be kept under similar homogenous and safe lighting conditions during housing, transport and house-keeping tasks such as the cleaning and sanitization of cages and rack holders, in order to avoid changes in biological rhythms, which could, in turn, affect parameters associated with behavior and physiology (Boxes 1, 2).

\section{Nocturnal Dim Light}

In animal holding rooms, it is common to see light during the night through translucent observation windows and around doorframes as a result of the leakage of white light originating from constantly illuminated corridors. It is also frequent to expose animals to occasional dim red light during experimental procedures to facilitate tasks in the dark. Some researchers believe that it is possible to expose laboratory animals to low intensities of light similar to those experienced naturally by rodents at night (much like a moon-like glow, <1 lux) (114) and that this type of exposure is not harmless to health and will not cause functional changes in the circadian system. In contrast, light exposure during the night can have adverse effects on laboratory animals even at intensities below the thresholds required to stimulate light-responsive neurons in the SCN $(0.1$ 


\section{Box 1 | Tips to measure light intensity}

It is recommended to measure light levels using radiometric units based upon unweighted power measurements (e.g., $\mu \mathrm{W} / \mathrm{cm}^{2}$ ) in place of lux measurements (100).

Light intensity decreases with the square of the distance from its source (97) and light measurements depend on placement and orientation of the light meter in relation to the light source. Most cages for rodents have the food- and water-bottle holder as part of the lid, which systematically changes light intensity when compared to uncovered cages. To get reliable values, the actual light intensity checks must be performed with the light meter vertical to the light source at the animal's eye level while the cage is covered (with bottles and food), keeping the habitat intensity as imperturbable as possible during this procedure.

Compared to clear plastic cages, tinted cages alter the photic environment and disrupt endocrine and metabolic circadian rhythms in albino rats (101) Thus, care must be taken when exchanging cages to maintain the same type of colored box. Therefore, transparency/color of the boxes must be indicated in Materials and Methods when publishing the results.

\section{Box 2 | Recommendations}

Cyclic light entrainment, is essential to maintain the robustness of the oscillators and circadian integrity.

Animals must be under the regular support of an LD cycle with clear contrast between day and night, and with similar lighting conditions during the diurnal phase and complete darkness (0 lux) during the nocturnal phase.

Light intensity should be monitored regularly within the cage at the animal's eye level to avoid experimental variability due to fluctuating lighting conditions.

- The lighting intensity inside of the home cage must be highly consistent between cages.

The circadian system becomes sensitive to photic input at night. Thus, light pollution should be avoided, even low intensities of any color. To perform tasks, or during routine maintenance under darkness, use infrared goggles or maintain red-light intensity at 0 lux at the animal's eye level.

The gestational or lactational photoperiods can shape behavior and physiology in the short- and long-term. Ask your provider for a report about the "lighting history" of your animals (LD cycle, intensity, and spectral transmittance) to confirm normal development and good health, and to adopt the appropriate habituation period to stabilize biological functions.

lux in the rat and 1 lux in the hamster) and at wavelengths to which mRGCs are practically unresponsive (red light) $(16,115)$. However, phototransduction via the rods, which are the most sensitive of the photoreceptors, even at low light intensities, converges on mRGCs (4).

Dim illumination at night ("light pollution") resets the circadian time-keeping system (115) of both the central and peripheral clocks, resulting in maladaptive or dysfunctional rhythms that increase the risk for chronic health conditions. Even a $1 \mathrm{~h}$ pulse of dim white light during the dark phase is enough to induce sleep in mice (19). Compared to the dark (0 lux), dim white light at night $\left(\mathrm{DWL}_{\mathrm{N}}\right)$ exerts both short- and longterm effects on the molecular clock, physiology, metabolism, hormonal rhythms, behavior, mood, hippocampal morphology, and cognition (Table 1). Dauchy et al. (130) described the detailed changes that can be made to a traditionally designed animal room in order to avoid light pollution, and how these improvements impact on the circadian regulation of biological rhythms.

At 5 lux, DWL $L_{N}$ reduced post-weaning growth rates and had long-lasting effects by increasing anxiety-like and fear-like behavior and the fearful responses to foot-shock in adults that had been exposed pre-and/or post-natally $(111,116)$. According to the period of exposure during rearing, the metabolic functions during adulthood are affected differently by $\mathrm{DWL}_{\mathrm{N}}$. Weanling mice, exposed since they were juveniles or adolescents, showed disrupted timing of food intake during adulthood by phase advancement of eating time and progressively increased daytime food intake; however, only males that had been exposed since adolescence showed increased body mass and gonadal fat mass relative to their dark counterparts in adulthood. During adulthood, none of these animals expressed alterations in glucose tolerance (117). In contrast to exposure at a younger age, exposure to $\mathrm{DWL}_{\mathrm{N}}$ during adulthood reduced glucose tolerance and increased body mass; these are both factors that are indicative of a pre-diabetic-like state (118). More recently, Stenvers et al. (127) showed that in adults, $\mathrm{DWL}_{\mathrm{N}}$ exposure reduced food intake and energy expenditure without affecting either body weight or impaired glucose tolerance. Certain differences in experimental procedures, such as the period of adaptation to $\mathrm{DWL}_{\mathrm{N}}$, and the methodology used during testing, could be important factors for such discrepancy. These developmentdependent alterations in metabolic energy homeostasis were associated with the disruption of circadian expression in crucial components of the molecular circadian clock in both the SCN and peripheral tissues that regulate metabolic functions. In particular, post-weaning exposure beginning at the juvenile or adolescent stage increases and decreases the amplitude of daily rhythm in the hypothalamic Clock and the expression of Rev-ERB in adulthood, respectively (111). However, during adulthood, $\mathrm{DWL}_{\mathrm{N}}$ attenuates the rhythmic expression of the core circadian clock genes Per1 Per2, Cry1, and Cry2 and PER1 and PER2 in the SCN, along with Bmal1, Per1, Per2, Cry1, and Cry 2 and Rev-ERB in the liver and adipose tissue (119).

Five lux of $\mathrm{DWL}_{\mathrm{N}}$ also induces maladaptive behaviors such as reduced sleep efficiency, depression and cognitive impairment. The regulation of circadian sleep-wake rhythm, and synchronicity with the light-dark cycle, is achieved by both oscillators of the SCN via the SPV and mainly the DMH which conveys circadian information to both sleep and wake mechanisms $(15,24,54,131-133)$. DWL $_{N}$ progressively reduces the amplitude of the sleep-wake circadian rhythm by gradually reducing sleep during the light (inactive) phase, but leaving the daily total sleep amount unchanged (127). These intrusions of waking episodes during the light phase reduce the amplitude of the daily rhythm of beta frequencies $(16-19 \mathrm{~Hz})$ and notably slow wave activity during non-rapid eye movement (non-REM) (127), both under strong influence from the endogenous circadian clock (134). It has been suggested that desynchronization between intra-SCN-oscillators was responsible for this circadian dysregulation, as shown by an endogenous free-running rhythm in locomotor activity with a period of $\sim 25 \mathrm{~h}$ next to the 
TABLE 1 | Summary of the main deleterious effects of dim white light at night vs. Dark (0 lux) on laboratory animal health.

\begin{tabular}{|c|c|c|c|c|}
\hline & Strain & $\begin{array}{l}\text { Period of } \\
\text { exposure-sex }\end{array}$ & Effects & References \\
\hline \multirow[t]{9}{*}{ 5lux } & & $\begin{array}{l}\text { - Prenatal } \\
\text { - Prenatal to P21 } \\
\text { - P21 } \\
\text { or } 9\end{array}$ & $\begin{array}{l}\downarrow \text { post-weaning growth rates } \\
\text { In adulthood: } \\
\uparrow \text { anxiety-like behavior } \\
\uparrow \text { fearful responses to footshock }\end{array}$ & $(116)$ \\
\hline & & $\begin{array}{l}\text { - P21 to } \\
\text { adulthood } \\
\text { - P35 to } \\
\text { adulthood } \\
0^{7}+\end{array}$ & $\begin{array}{l}\text { In adulthood: } \\
\uparrow \text { anxiety-like behavior } \\
\uparrow \text { fear-like behavior } \\
\uparrow \text { fearful responses to footshock (under dim light since P35) } \\
\uparrow \text { clock amplitude gene expression in hypothalamus } \\
\downarrow R \text { Rev-ERB gene expression in hypothalamus }\end{array}$ & $(111)$ \\
\hline & $\begin{array}{l}\text { Mice (Swiss } \\
\text { Webster) }\end{array}$ & $\begin{array}{l}\text { - P21 to } \\
\text { adulthood } \\
\text { ơ } q\end{array}$ & $\begin{array}{l}\text { In adulthood: } \\
\text {-no change in body mass } \\
\uparrow \text { day-time food intake (females ate more than males) } \\
\text {-no change in gonadal fat mass } \\
\text {-no change in locomotor activity } \\
\text {-no change in hepatic clock genes expression } \\
\text {-does not affect glucose } \\
\text { tolerance } \\
\text {-no change in 24-h food consumption }\end{array}$ & $(117)$ \\
\hline & & $\begin{array}{l}\text { - P35 to } \\
\text { adulthood } \\
0^{\top} q\end{array}$ & $\begin{array}{l}\text { In adulthood: } \\
\uparrow \text { body mass (males) } \\
\uparrow \text { day-time food intake (males) } \\
\uparrow \text { gonadal fat mass (males) } \\
\text {-no change in locomotor activity } \\
\text {-no change in hepatic clock genes expression } \\
\text {-does not affect glucose } \\
\text { tolerance } \\
\text {-no change in 24-h food consumption }\end{array}$ & $(117)$ \\
\hline & & & -overreaction of immune system & $(120)$ \\
\hline & $\begin{array}{l}\text { Mice } \\
(\mathrm{C} 57 \mathrm{bl} / 6)\end{array}$ & $\begin{array}{l}\text { Adult } \\
\sigma^{T}\end{array}$ & $\begin{array}{l}\text {-anxiety-like phenotype } \\
\text { - no change in circadian pattern of locomotor activity } \\
\downarrow \text { power of the locomotor activity rhythm }\end{array}$ & $(121)$ \\
\hline & $\begin{array}{l}\text { Mice } \\
(\mathrm{C} 3 \mathrm{H} / \mathrm{HeNH} \mathrm{sd})\end{array}$ & $\begin{array}{l}\text { Adult } \\
\sigma^{\pi}\end{array}$ & $\begin{array}{l}\text {-depressive-like phenotype } \\
\uparrow \text { body mass } \\
\downarrow \text { hippocampal BDNF gene expression }\end{array}$ & $(122)$ \\
\hline & & $\begin{array}{l}\text { Adult } \\
0^{\pi}\end{array}$ & $\begin{array}{l}\text {-depressive-like phenotype } \\
\text {-no change in locomotor activity } \\
\downarrow \text { dendritic length in dentate gyrus and CA1dendrites } \\
\text {-impaired learning and memory }\end{array}$ & $(123)$ \\
\hline & $\begin{array}{l}\text { Rat (Nile } \\
\text { grass) }\end{array}$ & $\begin{array}{l}\text { Adult (wild caught } \\
\text { background) } \\
\bigcirc^{\pi}\end{array}$ & $\begin{array}{l}\uparrow \text { immunological capabilities } \\
\uparrow \text { plasma corticosterone levels during active phase }\end{array}$ & $(124)$ \\
\hline
\end{tabular}


TABLE 1 | Continued

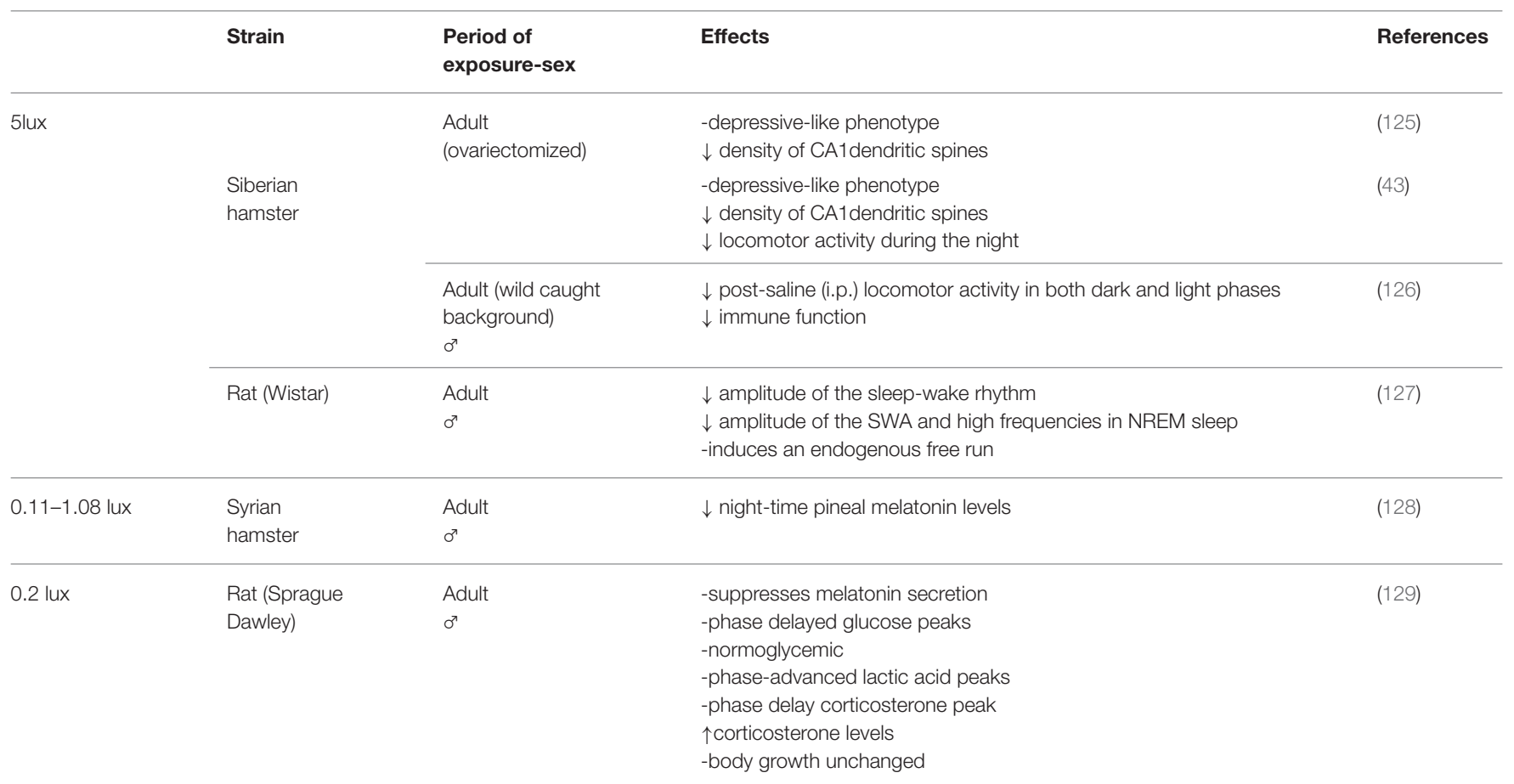

BDNF, brain-derived neurotrophic factor; LD, light-dark cycle; P, postnatal day; SWA, slow-wave activity; SCN, suprachiasmatic nucleus; ZT, zeitgeber time.

entrained 24-h period (127). However, there is some disparity over this issue because investigators found no difference in the circadian pattern or daily locomotor homecage activity in mice $(118,121)$ or in diurnal rats $(123)$. Moreover, depression is a persistent disorder that impairs mental and physical health. This condition has been historically associated with clock-related genes and dysfunction of circadian rhythms, particularly in terms of sleeping and waking (91, 135-138). Because of these alterations in the circadian system, adult nocturnal $(43,121$, $122,125)$, and diurnal rodents (123) under $\mathrm{DWL}_{\mathrm{N}}$ have been shown to exhibit a depressive-behavioral phenotype. Under $\mathrm{DWL}_{\mathrm{N}}$, adults also show reduced hippocampal expression of the brain-derived neurotrophic factor (BDNF) gene (122), a neuroprotective growth factor responsible for the growth and function of nerve cells and fundamental for plasticity, learning and memory. Hence, $\mathrm{DWL}_{\mathrm{N}}$ make these animals more susceptible to stress-oxidative damage (139) and impairs spatial learning task performance and memory (123). Such changes in performance and memory are related to lower dendritic length in the dentate gyrus and the Cornu Ammonis 1 (CA1) in male diurnal rats (123), and a reduction in spine density (125) on the apical and basilar dendritic branches of CA1 pyramidal neurons in ovariectomized hamsters (43) which was not found in diurnal male rats (123). This discrepancy could be ascribed to the fact that ovariectomy per se causes a profound decrease in dendritic spine density in CA1 pyramidal cells of the hippocampus (135).

At 5 lux, DWL $L_{N}$ is also known to have a profound effect on the immune system in different species. When exposed to pathogens, diurnal rats (from a wild stock background) showed enhanced immune reactions that were associated with an increased concentration of plasma corticosterone during the active phase (124), while inbred laboratory mice over-reacted and showed elevations of the inflammatory response in the peripheral and central nervous system, along with sickness behavior (120). In addition, research has shown an impairment of immunological capabilities in hamsters derived from wild caught stock and held under an inverse LD cycle (126). It is possible that the disparity shown in previous studies could be attributed to certain critical aspects of methodology and differences in the resistance/susceptibility of the immune system between species. For example, laboratory mice show greatly reduced survival when exposed to the pathogen at the early evening (140). Moreover, delayed-type hypersensitivity (DTH) has been assessed during the rest period in hamsters and during the active period in diurnal rats; data indicate that the differential immunological outcomes could be related to daily DTH variation (124). Furthermore, hamsters and diurnal rats, when derived from wild-caught stock, may still retain some wild immunological traits (141) that differ from the antigen-inexperienced immune system of inbred laboratory mice.

Aside from illuminance, another property worthy of consideration is the wavelength of light at night. Certain wavelengths play a more relevant and efficient role and exert a greater perturbing effect on the circadian system than others. Green light exerts the maximum phase shift of locomotor activity (142), and blue light is the most efficient in suppressing pineal melatonin levels, followed by green light and yellow light, while near-ultraviolet and red light are the least efficient 
(143). More recently, Bedrosian et al. (43) conducted a study in ovariectomized hamsters that investigated the effect of different wavelengths of dim light (5 lux) on SCN-activation, mood, behavior and hippocampal cell proliferation. In line with previous studies, chronic $\mathrm{DWL}_{\mathrm{N}}$ produces a depressivebehavioral phenotype $(121-123,125)$, although mood disorder was considerably more pronounced in animals under dim blue light at night $\left(\mathrm{DBL}_{\mathrm{N}}\right)$ (43). Moreover, like $\mathrm{DWL}_{\mathrm{N}}(43,125)$, $\mathrm{DBL}_{\mathrm{N}}$ reduced the number of dendritic arbors in the CA1 region of ovariectomized hamsters (43). Furthermore, unlike juvenile and adolescent mice (117), ovariectomized hamsters exposed to $\mathrm{DWL}_{\mathrm{N}}$ expressed reduced locomotor activity in holding cages during the dark phase with $24 \mathrm{~h}$ lower power than a nightly dark control group, while dim red light $\left(\mathrm{DRL}_{\mathrm{N}}\right)$ resulted in an increase of activity. $\mathrm{DBL}_{\mathrm{N}}$ did not significantly affect total activity but induced the greatest reduction in the $24 \mathrm{~h}$ power of activity rhythm (43). Moreover, during the early subjective night, a 5 lux brief pulse of $\mathrm{DWL}_{\mathrm{N}}$, and notably of $\mathrm{DBL}_{\mathrm{N}}$, activated the retinorecipient-SCN region, in a manner similar to a 150-lux pulse of white light (43). In agreement with this finding, a pulse of blue light (250 lux) during the dark phase evoked the greatest increase of Fos, Per1, and Per2 expression in the SCN and the adrenal gland, resulting in the highest levels of corticosterone secretion, which are normally associated with behavioral arousal (20). It is worth noting that while 250 lux blue light evokes higher gene induction in both the SCN and adrenal gland resulting in higher corticosterone levels and wake, the same intensity of green light produced a greater response in the major sleep promoting area (the ventrolateral preoptic area, VLPO), lower responses in the adrenal gland and corticosterone levels, and induces sleep. This opposite wavelength effect is melanopsin-dependent and provided evidence of two potentially different pathways with different spectral sensitivities for the wakefulness and sleep-promoting induction of light in nocturnal rodents (20).

To assess the effect of continuous dim light at night, all of the studies mentioned above used 5 lux night-time light, which is five times brighter than maximal moonlight ( $<1$ lux). However, it is important to highlight the fact that lower intensities of light can also affect the circadian timing system.

$\mathrm{DWL}_{\mathrm{N}}$ of low light intensity $\left(0.2\right.$ lux; $\left.0.08 \mu \mathrm{W} / \mathrm{cm}^{2}\right)$ disrupts the normal circadian output from the peripheral clocks (144). Indeed, peaks in glucose plasma concentration were phasedelayed by $4 \mathrm{~h}$ although animals remained normoglycemic throughout the entire $24-\mathrm{h}$ period. Plasma lactic acid concentration remained unchanged, although peak levels were phase-advanced by $4 \mathrm{~h}$, thus increasing its level of uptake during the night; corticosterone showed elevated daily plasma levels with peak amplitude delayed by $4 \mathrm{~h}$. Plasma levels, and the diurnal rhythm of total fatty acid and lipid fractions, along with dietary and water intake and body growth rate, were similar to a 12:12 LD cycle without light pollution (129). Light is a key factor that controls the night-time secretion of melatonin from the pineal gland (144) and at 0.20 or $1.08 \mathrm{lux}, \mathrm{DWL}_{\mathrm{N}}$ suppresses the levels of melatonin in both the plasma (129) and pineal gland (128) of rats and hamsters, respectively, in a manner similar to nightly white bright light (300 lux) (129). As melatonin restricts tumor growth (145), rats exposed to 0.20 lux DWL $\mathrm{L}_{\mathrm{N}}$ also showed an enhanced tumor growth rate $(146,147)$. Even low intensity green light (0.005 lux) may entrain the activity rhythms of hamsters exposed to different entrainment paradigms (148).

In short, animals must be protected from nightly light exposure at any intensity and wavelength. The studies described herein clearly highlight that there is a clear connection between dim light at night and maladaptive behavioral and physiological outcome with both short- and long-term effects. Compared to the dark (0 lux), light spectral transmittance associated with a blue wave-length (white light and notably, blue light) has the most perturbing effect upon the circadian system, behavior, synaptic plasticity, metabolic function, immune system, mood and cognition, even at very low intensities. These behavioral and physiological consequences would be consistent with the coding of different wavelength sensitivities attributed to each type of photoreceptor, and the predominant participation of melanopsin-RGCs (which are particularly sensitive to blue light) in order to convey the stimulus to circadian and non-circadian systems.

\section{Constant Darkness}

The synchronization of behavioral and physiological circadian rhythms can only be achieved through the entrainment of both SCN oscillators by a time signal environment with circadian characteristics close to the solar LD cycle. In the absence of light, and without other external time cues, the period of the circadian rhythms can be controlled by the intrinsic oscillation of their specific central clock (referred to as "free running rhythm") $(9,27)$; these rhythms then begin to free run with different period lengths and a lower amplitude $(34,149)$. This tool is used by chronobiologists to eliminate entrainment effects by light and therefore "unmask" the endogenous rhythm created by the machinery involved in the specific central clock.

Despite the elevated risk of depression in response to limited light exposure/intensity $(138,150)$, the consequences of longterm total darkness (free-running conditions) on behavior and neuronal systems were only reported a few years ago in laboratory animals $(151,152)$. For example, rats under complete darkness (0 lux) for several weeks exhibit distinct behavioral and anatomical features that are characteristic of depressed patients (Table 2). Behaviorally, these animals exhibited a delayed sleep phase and a lower amplitude sleep-wake circadian rhythm which was caused by an increase in sleep during the active period (151); these animals also showed increased immobility in a modified forced swim test (FST), increased locomotor activity in a novel environment, and a sensitized response to subsequent stressors (152). Anatomically, these animals expressed increased levels of apoptosis in the three monoaminergic systems associated with the pathology of depression, namely the noradrenergic (NA)-locus coeruleus (LC), the serotoninergic-raphe and the dopaminergic-ventral tegmental area systems, as well as a significant and continuous reduction in the number of NA boutons in the frontal and prefrontal cortex $(151,152)$. Longterm light deprivation (DD) did not affect body weight gain or adrenal weight, indicating that it is not stressful and therefore that damage to the NA-LC was not the result of chronic 
TABLE 2 | Summary of the main deleterious effects of constant darkness (0 lux) on laboratory animal health.

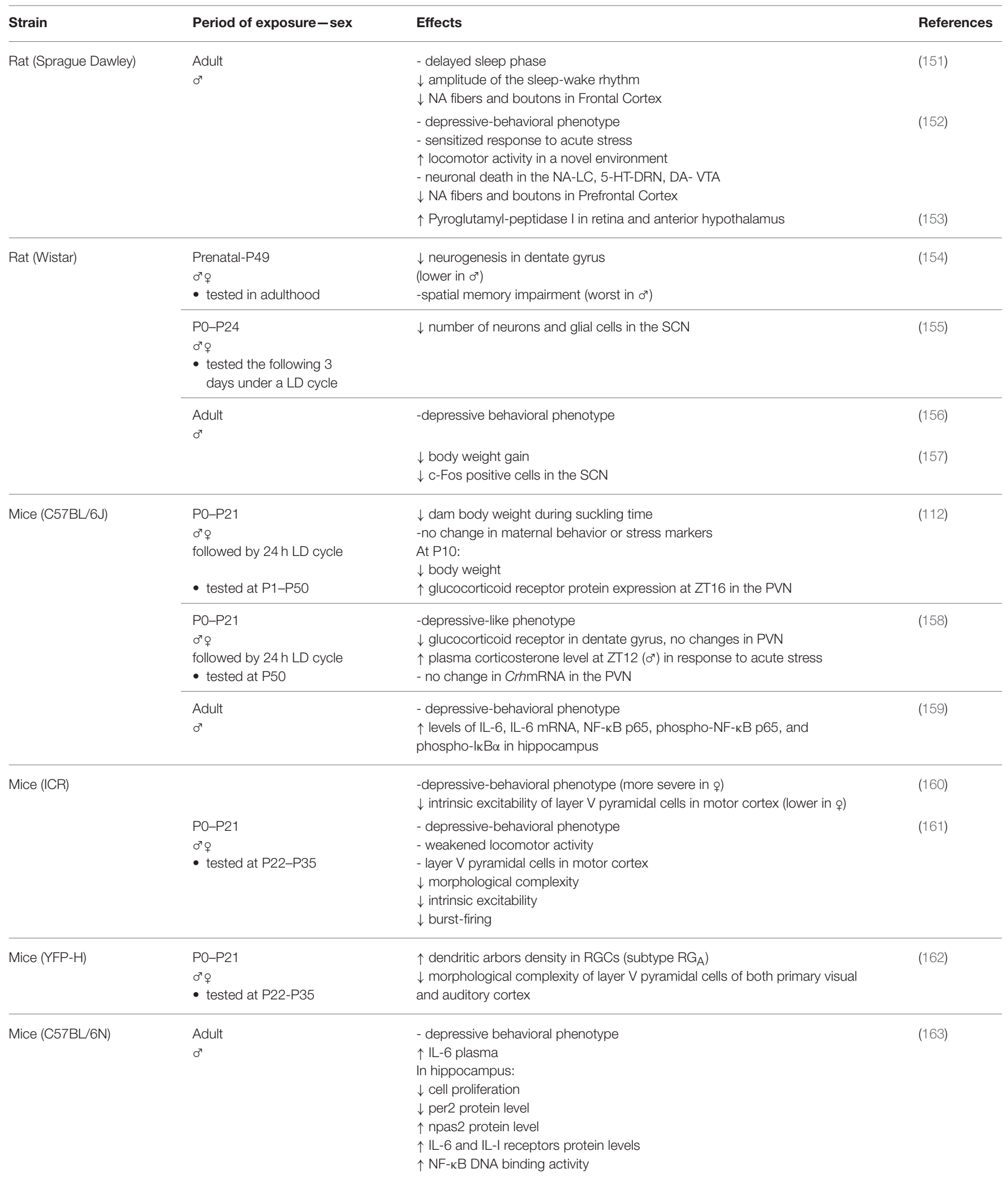

BDNF, brain-derived neurotrophic factor; DA, dopaminergic; VTA, ventral tegmental area; LD, light-dark cycle; NA, noradrenergic; LC, locus coeruleus; P, postnatal day; RGCs, retinal ganglion cells; serotoninergic (5-HT)-dorsal raphe nucleus; SWA, slow-wave activity; SCN, suprachiasmatic nucleus, ZT, zeitgeber time. 
stress (152)]. In this study, apoptotic death was progressive but could be restrained by the chronic administration of the tricyclic antidepressant desipramine, which also causes NA axonal regrowth and amelioration of the depressive behavioral phenotype, thus validating light-deprived rats as a non-stressful and genetically-intact model of depression (152). The depressive profile induced by light deprivation is not an acute effect, since an extension of $2 \mathrm{~h}$ to the dark period of LD animals (12:14) for 1 day did not affect immobility time during FST during the last hour of darkness (152). These results suggested that the absence of light input to brain centers which control mood disorders may be involved in the etiology of depression. As for the neural component, we originally proposed that the absence of light input would interrupt the synchronism between the SCN oscillators and dissociate rhythmic outputs, thus leading to depression after the dysregulation of the transynaptic efferent circuits that modulate the brain's monoaminergic systems and their associated behaviors (sleep, arousal, motivation, and mood) (151, 152). In agreement, more recently, we showed that a depressive phenotype can emerge from the desynchronization of cellular oscillators within the master circadian clock itself (164), suggesting for the first time in a genetically and neurologically intact animal, that the biological clock can exert functional implications upon the etiology of mood disorders and the specific mechanisms which underlie the beneficial effects of bright light therapy. Certainly, an impact of DD on the direct photic regulation on sleep and mood cannot be ruled out.

Subsequently, several studies have confirmed our results and additionally reported a range of other deleterious effects associated with DD. For example, light-deprived rodents expressed a depression-like phenotype (112, 156-161, 163), with more severe symptoms evident in females than males (160). Furthermore, in light-deprived adults, the enzymatic activity of pyroglutamyl-peptidase I in the retina, and anterior hypothalamus, was increased, thus indicating dysregulation in the metabolism of neuropeptides in the nervous system including alterations in reproductive function (153). The absence of photic stimuli also reduced neuronal activation in the SCN without affecting the circadian rhythmicity of corticosterone and melatonin plasma levels and increased and decreased body weight gain after 3 and 7 weeks, respectively, without affecting daily food ingestion (157). However, we did not find any differences in body weight gain after 3-6 weeks in DD rats (152). We should also mention that these authors have previously submitted animals to an inverted LD cycle and weighed them after behavioral stressful tests (by their characteristic overreaction to stress, the body weight of these animals may also have been affected), while our DD animals were previously housed in a 12:12 LD cycle and weighed before the behavioral test.

Apoptosis, along with neurodegeneration and inflammatory diseases, is associated with an accumulation of oxidative damage caused by the overproduction of free radicals such as reactive oxygen species (ROS) $(165,166)$. Accumulative oxidative stress reduces the levels of BDNF (167), a neurotropin that promotes neuronal survival, and its synaptic plasticity effectors, synapsin I and cAMP response element binding protein (CREB) (167,
168). Increased oxidative stress and reduced BDNF expression and/or function, particularly in the hippocampus, have also been implicated in both the pathophysiology of major depression and the typical overreaction to stress $(169,170)$. Confirming light-deprived animals as a model of depression, DD was shown to aggravate the outcome of oxidative stress, as shown by proinflammatory processes in the hippocampus $(159,163)$ which impaired neural plasticity and neurogenesis resulting in a subsequent deficit of learning (154), susceptibility to stress (152), and reduced c-Fos and CREB expression in several limbic areas involved in the reward and motivation mechanism (171). The depressive behavioral phenotype, inflammatory profile, and associated hippocampal neurodegeneration correlated with the DNA methylation-related chromatin remodeling process (172) that regulates neuronal activity dependent of BDNF gene expression (173). It was suggested that the circadian system would contribute to cellular homeostasis by regulating the expression of neuroprotective proteins that curtail oxidative damage and prevent synaptic damage in the nervous system (174). In agreement with this, transgenic mice featuring the knockout of the brain-specific clock genes Bmall or Clock and neuronal PAS domain protein 2 (Npas2) show severe astrogliosis, oxidative damage and exacerbated neurodegeneration (175), thus suggesting that alterations in the hippocampal protein levels of the clock genes Per 2 and Npas 2 induced by DD (163) would be involved in neuronal death, and the morphological and synaptic changes described previously. This action would be facilitated by increased binding activity of NF- $\kappa$ B DNA (163), a transcription factor that is activated by ROS and regulates the inflammatory and immune response (165). Moreover, Qi et al. (176) recently found that the apoptosis triggered by DD extends to the liver due to the oxidative damage caused by the overproduction of ROS after a marked reduction in the mRNA levels of antioxidant enzymes.

The harmful effects of DD occur relatively swiftly and cannot be rapidly undone. In a previous study, 7 days were enough to elicit a depressive behavioral phenotype that could not be reversed by $1-2$ days in 12:12LD (156). This time period was also sufficient to reduce levels of BDNF mRNA and protein expression in the visual cortex and affect the regulation of hippocampal genes that are critical for neural plasticity (172).

The effects of the absence of light when the SCN is still immature and has not yet completely configured its synaptic connections $(78,80)$ are reflected by long-term consequences on circadian rhythm outputs, clock gene expression, mood, physiology, stress markers, neuronal function, plasticity, and cognition. During the suckling period, DD causes a reduction in the number of neuronal and glia cells responsible for the coupling between SCN oscillators (155). This structural alteration will certainly affect the development and performance of the SCN, which may, in turn, desynchronize rhythms and modify animal physiology and behavior. Restricted to certain developmental periods, light deprivation causes morphological and physiological ontogenetic changes when compared against normal maturational processes, which may result in a depressive phenotype in juveniles and into adulthood, together with other benchmarks of clinical depression which are not prevented by 
post-weaning housing under a 12:12 LD cycle $(158,160,161)$. In particular, pups raised up to the weaning stage in DD, followed by standard 12:12 LD conditions, showed a depressivelike phenotype during adulthood, with reduced expression of the glucocorticoid receptor in the hippocampus but without changes in the paraventricular nucleus (PVN). These effects were seen with higher plasma corticosterone levels in response to acute stress only in males, indicating sexual dimorphic sensitivity in the nervous system during development to the lighting conditions (158). Only at 10 days of age (P10), did pups raised in DD show reduced body weight and increased expression of glucocorticoid receptor mRNA in the paraventricular nucleus (PVN), thus leading to a higher level of activity in the hypothalamic-pituitaryadrenal axis (112). Light deprivation did not alter the levels of maternal stress markers and did not change maternal care behavior (except for a different temporal distribution) but did reduce body weight in dams during the suckling stage (112). This result ruled out the fact that altered maternal behavior may have been a factor responsible for the changes found in adults reared under DD and also highlight the absence of light as a main trigger that would affect the HPA axis only at a specific development stage. The absence of photic stimuli during the suckling period also reduced the morphological complexity of the primary visual and auditory cortical layer $\mathrm{V}$ pyramidal cells, with increased morphological complexity in a specific mRGC subtype $\left(\mathrm{mRGC}_{\mathrm{A}}\right.$ cells), as shown later during the pre- and peri-puberal periods, suggesting that postnatal DD promotes "cross-modal plasticity" among different neuronal systems during brain development (162). Moreover, light-deprived animals from the prenatal period to adulthood showed reduced levels of neurogenesis in the dentate gyrus, which was more severe in adult males than females and associated with subsequent impairment of spatial memory (154).

It was suggested that the dimorphic behavioral-depressive phenotype described in previously reared-DD juveniles was associated to weaker locomotor activity during stressful tests (161) and that this was related to the simplified morphological complexity and lower excitability of the motor cortical dendritic arbors of layer $\mathrm{V}$ pyramidal cells (the major output from the cortex) exhibited in cortical slices, principally from females $(160,161)$. We have previously shown that in adult rats under $\mathrm{DD}$, the increased immobility during FST was not caused by a deficit in motor activity or a response to salient stimuli. Indeed, these animals showed increased ambulatory activity in a novel environment (152). Moreover, and contrary to the findings of Lu et al. (160) and Zhang et al. (161) light deprivation did not affect motor tasks such as swimming and pawing during the FST (152). It is possible that exposure to DD during development has a major impact on the cortex than it does during adulthood. We cannot dismiss the fact that our animals were provided with a flotation aid to allow more confident motor behavioral scoring and guarantee that the escape deficit was primarily caused by DD treatment and not by the unnatural FST stressor.

Animals that are regularly used in research are born and grown, over many generations, under a regular 12:12 LD cycle with light intensities that differ from wild conditions. This difference in "lighting background" could predict the fact that the circadian system in these animals would evolve differently. It has become clear that unlike animals in the wild, laboratory rodents respond negatively to lighting conditions present in natural conditions (177). Constant darkness would be an unnatural condition for diurnal and nocturnal inbred laboratory rodents. Indeed, constant light deprivation became a very useful tool for studying the mechanisms involved in the etiology of depression and the identification of new and efficient therapeutic strategies. Furthermore, light-deprived animals are likely to represent a useful model for gaining new insights on the specific mechanisms which occur during brain/neuronal injury, such as neurodegeneration and inflammation and where the cell damage is induced spontaneously and not by impact/acceleration brain injury (178) or exposure to unnatural stressors $(179,180)$.

In short, like other aberrant lighting conditions (constant light, short day light) (14), light-deprived animals show anatomical, physiological and behavioral depression-related alterations, which are considered as clinical benchmarks of depression. In laboratory animals, light deprivation shapes the brain in developing pups and in adults, which end up with damaged neural systems, maladaptive behaviors, dysfunctional physiology, and impaired cognition, all of which are associated with oxidative damage. The detrimental effects of DD call for caution in the interpretation of experimental results and a re-evaluation of the use of "free-running" conditions. Such damage is progressive and the temporal evolution of its negative effects suggests that there is not a safe window for long-term experimental use.

There are still several key questions at stake. Is there a lightdependent process responsible for the neuroprotective/trophic effect? Is this process related to the well-known direct masking effect of light? Is the poor visual sensory environment a cause of depression? There would be one way to address these critical doubts. A non-photic conditioned stimulus (air flow) that was previously associated to an unconditioned stimulus (a light pulse) has the ability, by itself, to induce Fos expression in the SCN and phase shift the spontaneous activity and body temperature SCN-dependent rhythms during the subjective night, thus mimicking the effect of a pulse of light (181). This would be an alternative to keep the rhythms of light-deprived animals synchronized with the natural LD cycle. If the use of Pavlovian conditioning provides healthier light-deprived animals, then the neuroprotective/trophic effect of light per se, and the reduced sensory environment, could be discarded as principal factors for the genesis of the morphological, behavioral and physiological changes described previously; the synchronization of rhythms by light, known as the "masking effect of light" would be the key to this process.

\section{Dim Red Light Is Not an Alternative}

Certain housing facilities use red-tinted observation windows or hold animals under red light throughout the night to facilitate maintenance and experimental procedures. Like white light, exposure to nightly red light $\left(\mathrm{DRL}_{\mathrm{N}}\right)$ acts as a zeitgeber by altering the entrainment of circadian activity rhythms and suppresses 
melatonin (100). As mentioned earlier, $\mathrm{DRL}_{\mathrm{N}}$ (5 lux) significantly increased locomotor activity in holding cages during the dark phase compared to a control group without any light exposure during the night (43). At higher intensities (8 lux), DRL dramatically disrupted the rhythmic circadian pattern and altered the physiological parameters of nocturnal albino rats (182). Even though there was no significant difference in the phase and period of the circadian rhythm associated with melatonin, the amplitude was reduced by a suppression of peak-dark phase secretion to almost daytime values. Moreover, the daily rhythms of arterial plasma glucose and lactate concentrations, along with arterial $\mathrm{pO}_{2}$ and $\mathrm{pCO}_{2}$, were almost identical to controls, although their levels were higher over the 24-h day. Moreover, corticosterone and insulin showed a disrupted circadian rhythm; peaks of plasma corticosterone and insulin were both phase-advanced, and the $24 \mathrm{~h}$-day concentrations were reduced. In terms of leptin, $24 \mathrm{~h}$-cycling was absent, the plasma peak was phase-delayed and the $24 \mathrm{~h}$-day concentration was increased. Furthermore, the plasma levels of total fatty acid were elevated throughout the 24-h day and the circadian rhythm was abrogated [(182). Even at very low intensities $(<1$ lux), short-term (2h) DRL $\mathrm{D}_{\mathrm{N}}$ exposure entrains wheel-running activity and the time of ovulation in light-deprived animals (free-running animals). This occurs by phase advancement when applied at the end of their active period, and by phase delay when applied at the beginning of their active period (98, 183).

Constant dim red light (DimRR) is far from an ideal option instead of DD because it also promotes circadian dysfunction. In adult nocturnal rats, DimRR, at very low intensities (0.5-1 lux), progressively reduces the amplitude of sleep-wake by decreasing the amount of sleep during the rest phase. This changes the rhythmic pattern of locomotion and drinking activities, along with brain and intraperitoneal temperature, as well as increasing the number of REM sleep episodes during the active phase (184). Long-term DimRR at higher intensity (5 lux) generates freerunning locomotor activity $(185,186)$ and uncouples melatonin rhythm from that of locomotor activity and body temperature (185). Moreover, at 5 lux, DimRR slightly reduced the amplitude of the rhythm of Per1 mRNA expression in the SCN and noticeably increased the overall variability of Per1 mRNA expression in the SCN, the clock-controlled gene arylalkylamine $\mathrm{N}$-acetyltransferase (Aa-nat) mRNA in the retina and pineal gland (186), and the plasma levels of melatonin, although their circadian rhythm persisted $(185,186)$. These effects of DimRR on the circadian system would result in the loss of coupling between the $\mathrm{SCN}$-oscillators, thus affecting the temporal pattern and synchronization of behavioral and physiological rhythms (184-186).

In short, we must not underestimate the effect of red light, which effectively disrupts physiological and behavioral circadian rhythms. Consequently, red light, even at very low intensities, should not be regarded as functionally equivalent to darkness. For scientists who need to carry out tasks under darkness, it is extremely important to maintain light intensity at 0 lux for all wavelengths when measured at the animal's eye level.

\section{CONCLUDING REMARKS}

An increasing body of literature describes the immediate impact of light in the development of fetal rhythms and on the wellbeing of offspring and adults. Collectively, this literature aims to improve awareness in the scientific community with regard to the use of aberrant lighting conditions as a risk factor. Without light-dark transitions to reset the principal clock, the risk for lifelong physiological and behavioral maladaptive responses is increased. Dim light at night, as well as DD, can profoundly alter the circadian timing system along with the downstream control it exerts on mood, behavior, DNA repair, apoptosis, synaptic plasticity, cellular proliferation, endocrine and metabolic function, the immune system, and cognition. We cannot underestimate a direct influence of these lighting conditions on mechanisms that are independent of the circadian system, but further research is needed to understand how both direct and indirect pathways interplay and contribute to the disruptive effects of dim light at night and DD on health and wellbeing.

It is important to ensure that we control lighting in a stricter manner and to give broader consideration to the potential effects of light leakage at night. Animal facilities that do not comply with the Guide for the Care and Use of Laboratory Animals must be redesigned in order to improve blackout conditions. Even minimal "accidental" light exposure during the dark phase should not be disregarded, independently of the intensity and wavelength. Furthermore, a complete report, which describes lighting conditions from prenatal and postnatal periods, including the intensity and spectrum of light, should be communicated by providers to the customer. It is important that suppliers provide us with a detailed history of the lighting conditions in which our laboratory animals were reared in order to verify that such animals are appropriate for research.

In addition, the color and intensity of light at the animal's eye level need to be specified and published in detailed scientific protocols to avoid substantial variations in quality and thus increase our chances of obtaining reliable and reproducible results.

Constant darkness, which is used by chronobiologists to release an individual's rhythms of the main zeitgeber (the light), should not be considered a natural environment but rather, as a bad scenario for the wellbeing and health of nocturnal and diurnal laboratory animals. Indeed, light deprivation became an inexpensive and simple method with which to produce an anatomical, physiological and behavioral depressive phenotype in laboratory animals. Longterm light deprivation can exacerbate oxidative damage by disrupting the expression of clock genes and weakening the molecular substrates required for maintaining neuronal and synaptic function. Therefore, light should not be dismissed as an environmental condition when research studies are evaluating normal function in the whole body of laboratory animals.

In conclusion, a stable $24 \mathrm{~h} \mathrm{LD}$ photoperiod with clear contrast between day and night, with safe light during the day and 
null light at night, is key to maintaining the circadian integrity of mammals from pre- and post-natal periods to adulthood, which in turn, will result in normal development and good health. Outside this criterion, the stability of biological function becomes altered and thus affects the wellbeing of animals, and experimental results in the short and long-term. Because of these reasons, experimental lighting conditions deserve special attention and should be periodically checked throughout the entire life of laboratory animals to provide an optimal effect and ensure good welfare. We need to reach a consensus on this matter so that we can adopt international standard criteria for photoperiods to be used for laboratory animals, which follow similar methodologies to measure the properties of light. Furthermore, the Institutional Animal Care and Use Committees should call for compliance with a universal set

\section{REFERENCES}

1. Altimus CM, Güler AD, Alam NM, Arman AC, Prusky GT, Sampath AP, et al. Rod photoreceptors drive circadian photoentrainment across a wide range of light intensities. Nat Neurosci. (2010) 13:1107-12. doi: 10.1038/nn.2617

2. Antle MC, Silver R. Orchestrating time: arrangements of the brain circadian clock. Trends Neurosci. (2005) 28:145-51. doi: 10.1016/j.tins.2005.01.003

3. Berson DM. Strange vision: ganglion cells as circadian photoreceptors. Trends Neurosci. (2003) 26:314-20. doi: 10.1016/S0166-2236(03)00130-9

4. Brown TM. Using light to tell the time of day: sensory coding in the mammalian circadian visual network. J Exp Biol. (2016) 219:1779-92. doi: $10.1242 /$ jeb. 132167

5. Butler MP, Silver R. Divergent photic thresholds in the non-image-forming visual system: entrainment, masking and pupillary light reflex. Proc Biol Sci. (2011) 278:745-50. doi: 10.1098/rspb.2010.1509

6. Cajochen C, Munch M, Kobialka S, Krauchi K, Steiner R, Oelhafen P, et al. High sensitivity of human melatonin, alertness, thermoregulation, and heart rate to short wavelength light. J Clin Endocrinol Metab. (2005) 90:1311-6. doi: 10.1210/jc.2004-0957

7. Dijk D-J, Archer SN. Light, sleep, and circadian rhythms: together again. PLoS Biol. (2009) 7:e1000145. doi: 10.1371/journal.pbio.1000145

8. Fisk AS, Tam SKE, Brown LA, Vyazovskiy VV, Bannerman DM, Peirson SN. Light and cognition: roles for circadian rhythms, sleep, and arousal. Front Neurol. (2018) 9:56. doi: 10.3389/fneur.2018.00056

9. Golombek DA, Rosenstein RE. Physiology of circadian entrainment. Physiol Rev. (2010) 90:1063-102. doi: 10.1152/physrev.00009.2009

10. Göz D, Studholme K, Lappi DA, Rollag MD, Provencio I, Morin LP. Targeted destruction of photosensitive retinal ganglion cells with a saporin conjugate alters the effects of light on mouse circadian rhythms. PLOS ONE (2008) 3:e3153. doi: 10.1371/journal.pone. 0003153

11. Hastings MH, Reddy AB, Maywood ES. A clockwork web: circadian timing in brain and periphery, in health and disease. Nat Rev Neurosci. (2003) 4:649-61. doi: 10.1038/nrn1177

12. Hattar S, Liao HW, Takao M, Berson DM, Yau KW. Melanopsincontaining retinal ganglion cells: architecture, projections, and intrinsic photosensitivity. Science (2002) 295:1065-70. doi: 10.1126/science.1069609

13. LeGates TA, Altimus CM, Wang H, Lee HK, Yang S, Zhao H, et al. Aberrant light directly impairs mood and learning through melanopsin-expressing neurons. Nature (2012) 491:594-8. doi: 10.1038/nature11673

14. LeGates TA, Fernández DC, Hattar S. Light as a central modulator of circadian rhythms, sleep and affect. Nat Rev Neurosci. (2014) 15:443-54. doi: $10.1038 / \mathrm{nrn} 3743$

15. Lu J, Zhang YH, Chou TC, Gaus SE, Elmquist JK, Shiromani P, et al. Contrasting effects of ibotenate lesions of the paraventricular nucleus and subparaventricular zone on sleep-wake cycle and temperature regulation. J Neurosci. (2001) 21:4864-74. doi: 10.1523/JNEUROSCI.21-13-04864. 2001 of rules and clearly explain how the failure to comply with such codes of practice could have very serious consequences for the animals.

\section{AUTHOR CONTRIBUTIONS}

The author confirms being the sole contributor of this work and approved it for publication.

\section{ACKNOWLEDGMENTS}

The author would like to thank Diego Golombek, Ph.D. for his comments on this manuscript. This work was supported in part by the Fundación Argentina de Estudio del Cerebro (FADEC) affiliated to the University of Buenos Aires, Argentina.

16. Meijer JH, Schwartz WJ. In search of the pathways for light-induced pacemaker resetting in the suprachiasmatic nucleus. J Biol Rhythms (2003) 18:235-49. doi: 10.1177/0748730403018003006

17. Milosavljevic N, Allen AE, Cehajic-Kapetanovic J, Lucas RJ. Chemogenetic activation of ipRGCs drives changes in dark-adapted (Scotopic) electroretinogram. Invest Ophthalmol Vis Sci. (2016) 57:6305-12. doi: 10.1167/iovs.16-20448

18. Morin LP. Nocturnal light and nocturnal rodents: similar regulation of disparate functions? J Biol Rhythms (2013) 28:95-106. doi: 10.1177/0748730413481921

19. Muindi F, Zeitzer JM, Colas D, Heller HC. The acute effects of light on murine sleep during the dark phase: importance of melanopsin for maintenance of light-induced sleep. Eur J Neurosci. (2013) 37:1727-36. doi: 10.1111/ejn.12189

20. Pilorz V, Tam SKE, Hughes S, Pothecary CA, Jagannath A, Hankins MW, et al. Melanopsin regulates both sleep-promoting and arousalpromoting responses to light. PLoS Biol. (2016) 14:e1002482. doi: 10.1371/journal.pbio.1002482

21. Schmidt TM, Chen SK, Hattar S. Intrinsically photosensitive retinal ganglion cells: many subtypes, diverse functions. Trends Neurosci. (2011) 34:572-80. doi: 10.1016/j.tins.2011.07.001

22. Stephenson KM, Schroder CM, Bertschy G, Bourgin P. Complex interaction of circadian and non-circadian effects of light on mood: shedding new light on an old story. Sleep Med Rev. (2012) 16:445-54. doi: 10.1016/j.smrv.2011.09.002

23. Tosini G, Ferguson I, Tsubota K. Effects of blue light on the circadian system and eye physiology. Mol Vis. (2016) 22:61-72.

24. Vujovic N, Gooley JJ, Jhou TC, Saper CB. Projections from the subparaventricular zone define four channels of output from the circadian timing system. J Comp Neurol. (2015) 523:2714-37. doi: 10.1002/cne.23812

25. Warren EJ, Allen CN, Brown RL, Robinson DW. Intrinsic light responses of retinal ganglion cells projecting to the circadian system. Eur J Neurosci. (2003) 17:1727-35 doi: 10.1046/j.1460-9568.2003.02594.x

26. Colwell CS. Rhythmic coupling among cells in the suprachiasmatic nucleus. J Neurobiol. (2000) 43:379-88. doi: 10.1002/10974695(20000615)43:4<379::AID-NEU6>3.0.CO;2-0

27. Colwell ChS, Witkovsky P, Rae Silver R. The Suprachiasmatic Nucleus (SCN): critical points. In: Colwell CS, editor. Circadian Medicine. Hoboken, NJ: Wiley Blackwell (2015). p. 37-55.

28. McMahon DG, Iuvone PM, Tosini G. Circadian organization of the mammalian retina: from gene regulation to physiology and diseases. Prog Retin Eye Res. (2014) 39:58-76. doi: 10.1016/j.preteyeres.2013.12.001

29. Mohawk JA, Green CB, Takahashi JS. Central and peripheral circadian clocks in mammals. Annu Rev Neurosci. (2012) 35:445-62. doi: 10.1146/annurev-neuro-060909-153128

30. Oster H, Damerow S, Kiessling S, Jakubcakova V, Abraham D, Tian J et al. The circadian rhythm of glucocorticoids is regulated by a gating 
mechanism residing in the adrenal cortical clock. Cell Metab. (2006) 4:16373. doi: $10.1016 /$ j.cmet.2006.07.002

31. Takahashi JS, Hong HK, Ko CH, McDearmon EL. The genetics of mammalian circadian order and disorder: implications for physiology and disease. Nat Rev Genet. (2008) 9:764-75. doi: 10.1038/nrg2430

32. Wright KP, Lowry CA, Lebourgeois MK. Circadian and wakefulness-sleep modulation of cognition in humans. Front Mol Neurosci. (2012) 5:50. doi: 10.3389/fnmol.2012.00050

33. Brown SA, Azzi A. Peripheral circadian oscillators in mammals. In: Kramer A, Merrow M editors. Circadian Clocks. Handbook of Experimental Pharmacology. Berlin; Heidelberg: Springer (2013). p. 45-66.

34. van Someren EJ, Riemersma-Van Der Lek RF. Live to the rhythm, slave to the rhythm. Sleep Med Rev. (2007) 11:465-84. doi: 10.1016/j.smrv.2007.07.003

35. Aston-Jones G, Chen S, Zhu Y, Oshinsky ML. A neural circuit for circadian regulation of arousal. Nat Neurosci. (2001) 4732-8. doi: 10.1038/89522

36. Buijs RM, van Eden CG, Goncharuk VD, Kalsbeek A. The biological clock tunes the organs of the body: timing by hormones and the autonomic nervous system. J Endocrinol. (2003) 177:17-26. doi: 10.1677/joe.0.1770017

37. Chou TC, Scammell TE, Gooley JJ, Gaus SE, Saper CB, Lu J. Critical role of dorsomedial hypothalamic nucleus in a wide range of behavioral circadian rhythms. J Neurosci. (2003) 23:10691-702. doi: 10.1523/JNEUROSCI.23-33-10691.2003

38. Pace-Schott EF, Hobson JA. The neurobiology of sleep: genetics, cellular physiology and subcortical networks. Nat Rev Neurosci. (2002) 3:591-605. doi: $10.1038 / n r n 895$

39. Altimus CM, Güler AD, Villa KL, McNeill DS, LeGates TA, Hattar S. Rodscones and melanopsin detect light and dark to modulate sleep independent of image formation. Proc Natl Acad Sci USA. (2008) 105:19998-20003. doi: $10.1073 /$ pnas. 0808312105

40. Hattar S, Lucas RJ, Mrosovsky N, Thompson S, Douglas RH, Hankins $\mathrm{MW}$, et al. Melanopsin and rod-cone photoreceptive systems account for all major accessory visual functions in mice. Nature (2003) 424:76-81. doi: 10.1038/nature01761

41. Panda, S, Sato TK, Castrucci AM, Rollag MD, DeGrip WJ, Hogenesch JB, et al. Melanopsin (Opn4) requirement for normal light-induced circadian phase shifting. Science (2002) 298:2213-6. doi: 10.1126/science.1076848

42. Ruby NF, Brennan TJ, Xie X, Cao V, Franken P, Heller HC, et al. Role of melanopsin in circadian responses to light. Science (2002) 298:2211-3. doi: $10.1126 /$ science. 1076701

43. Bedrosian TA, Vaughn CA, Galan A, Daye G, Weil ZM, Nelson RJ. Nocturnal light exposure impairs affective responses in a wavelength-dependent manner. J Neurosci. (2013) 33:13081-7. doi: 10.1523/JNEUROSCI.5734-12.2013

44. Studholme KM, Gompf HS, Morin LP. Brief light stimulation during the mouse nocturnal activity phase simultaneously induces a decline in core temperature and locomotor activity followed by EEG-determined sleep. Am J Physiol Regul Integr Comp Physiol. (2013) 304:R459-71. doi: 10.1152/ajpregu.00460.2012

45. Tsai JW, Hannibal J, Hagiwara G, Colas D, Ruppert E, Ruby NF, et al. Melanopsin as a sleep modulator: circadian gating of the direct effects of light on sleep and altered sleep homeostasis in Opn4(-/-) mice. PLoS Biol. (2009) 7:e1000125. doi: 10.1371/journal.pbio.1000125

46. Cailotto C, Lei J, van der Vliet J, van Heijningen C, van Eden CG, Kalsbeek A, et al. Effects of nocturnal light on (clock) gene expression in peripheral organs: a role for the autonomic innervation of the liver. PLoS ONE (2009) 4:e5650. doi: 10.1371/journal.pone.0005650

47. Kopp M, Meissl H, Korf HW. The pituitary adenylate cyclase-activating polypeptide-induced phosphorylation of the transcription factor CREB (cAMP response element binding protein) in the rat suprachiasmatic nucleus is inhibited by melatonin. Neurosci Lett (1997) 227:145-8. doi: 10.1016/S0304-3940(97)00312-1

48. McArthur AJ, Hunt AE, Gillette MU. Melatonin action and signal transduction in the rat suprachiasmatic circadian clock: activation of protein kinase C at dusk and dawn. Endocrinology (1997) 138:627-34. doi: 10.1210/endo.138.2.4925

49. Walton JC, Weil ZM, Nelson RJ. Influence of photoperiod on hormones, behavior, and immune function. Front Neuroendocrinol. (2011) 32:303-19. doi: 10.1016/j.yfrne.2010.12.003
50. de la Iglesia HO, Schwartz WJ. A subpopulation of efferent neurons in the mouse suprachiasmatic nucleus is also light responsive. Neuroreport (2002) 13:857-60. doi: 10.1097/00001756-200205070-00024

51. de la Iglesia HO, Cambras T, Schwartz WJ, Diez-Noguera A. Forced desynchronization of dual circadian oscillators within the rat suprachiasmatic nucleus. Curr Biol (2004) 14:796-800. doi: 10.1016/j.cub.2004.04.034

52. Beaulé C, Arvanitogiannis A, Amir S. Light suppresses Fos expression in the shell region of the suprachiasmatic nucleus at dusk and dawn: implications for photic entrainment of circadian rhythms. Neuroscience (2001) 106:24954. doi: 10.1016/S0306-4522(01)00313-X

53. Bernard S, Gonze D, Cajavec B, Herzel H, Kramer A. Synchronizationinduced rhythmicity of circadian oscillators in the suprachiasmatic nucleus. PLoS Comput Biol. (2007) 3:e68. doi: 10.1371/journal.pcbi.0030068

54. Cambras T, Weller JR, Anglès-Pujoràs M, Lee ML, Christopher A, DíezNoguera A, et al. Circadian desynchronization of core body temperature and sleep stages in the rat. Proc Natl Acad Sci USA. (2007) 104:7634-9. doi: 10.1073/pnas.0702424104

55. Lee ML, Swanson BE, de la Iglesia HO. Circadian timing of REM sleep is coupled to an oscillator within the dorsomedial suprachiasmatic nucleus. Curr Biol. (2009) 19:848-52. doi: 10.1016/j.cub.2009.03.051

56. Yan L, Karatsoreos I, Lesauter J, Welsh DK, Kay S, Foley D, et al. Exploring spatiotemporal organization of SCN circuits. Cold Spring Harb Symp Quant Biol. (2007) 72:527-41. doi: 10.1101/sqb.2007.72.037

57. Aton SJ, Huettner JE, Straume M, Herzog ED. GABA and Gi/o differentially control circadian rhythms and synchrony in clock neurons. Proc Natl Acad Sci USA. (2006) 103:19188-93. doi: 10.1073/pnas.0607 466103

58. van Diepen HC, Foster RG, Meijer JH. A colourful clock. PLoS Biol. (2015) 13:e1002160. doi: 10.1371/journal.pbio.1002160

59. Renna JM, Chellappa DK, Ross CL, Stabio ME, Berson DM. Melanopsin ganglion cells extend dendrites into the outer retina during early postnatal development. Dev Neurobiol. (2015) 75:935-46. doi: 10.1002/dneu. 22260

60. Morin LP, Shivers KY, Blanchard JH, Muscat L. Complex organization of mouse and rat suprachiasmatic nucleus. Neuroscience (2006) 137:1285-97. doi: 10.1016/j.neuroscience.2005.10.030

61. Bourgin P, Hubbard J. Alerting or somnogenic light: pick your color. PLoS Biol (2016) 14:e2000111. doi: 10.1371/journal.pbio.2000111

62. Campuzano A, Cambras T, Vilaplana J, Canal MM, Carulla M, DiezNoguera A. Period length of the light-dark cycle influences the growth rate and food intake in mice. Physiol Behav. (1999) 67:791-7. doi: 10.1016/S0031-9384(99)00196-1

63. Haus E, Smolensky M. Biological clocks and shift work: circadian dysregulation and potential long-term effects. Cancer Causes Control (2006) 17:489-500. doi: 10.1007/s10552-005-9015-4

64. Minors DS, Waterhouse JM, Wirz-Justice A. A human phase-response curve to light. Neurosci Lett. (1991) 133:36-40. doi: 10.1016/0304-3940(91)90051-T

65. Navara KJ, Nelson RJ. The dark side of light at night: physiological, epidemiological, and ecological consequences. J Pineal Res. (2007) 43:21524. doi: 10.1111/j.1600-079X.2007.00473.x

66. Sakellaris PC, Peterson A, Goodwin A, Winget CM, Vernikos-Danellis J. Response of mice to repeated photoperiod shifts: susceptibility to stress and barbiturates. Proc Soc Exp Biol Med. (1975) 149:677-80. doi: 10.3181/00379727-149-38877

67. Stevens RG, Brinard GC, Blsk DE, Lockley SW, Motta ME. Breast cancer and circadian disruption from electric lighting in the modern world. CA Cancer J Clin. (2014) 64:207-18. doi: 10.3322/caac.21218

68. Zelinski EL, Deibel SH, McDonald RJ. The trouble with circadian clock dysfunction: multiple deleterious effects on the brain and body. Neurosci Biobehav Rev. (2014) 40:80-101. doi: 10.1016/j.neubiorev.2014.01.007

69. Ecker JL, Dumitrescu ON, Wong KY, Alam NM, Chen SK, LeGates $\mathrm{T}$, et al.. Melanopsin-expressing retinal ganglion-cell photoreceptors: cellular diversity and role in pattern vision. Neuron (2010) 67:49-60. doi: 10.1016/j.neuron.2010.05.023

70. Hattar S, Kumar M, Park A, Tong P, Tung J, Yau KW, et al. Central projections of melanopsin-expressing retinal ganglion cells in the mouse. $J$ Comp Neurol. (2006) 497:326-49. doi: 10.1002/cne.20970 
71. Meijer JH, Watanabe K, Detari L, de Vries MJ, Albus H, Treep JA, et al. Chapter 12 Light entrainment of the mammalian biological clock. Prog Brain Res. (1996) 111:175-90.

72. Davis FC. Melatonin: role in development. J Biol Rhythms (1997) 12:498-508. doi: 10.1177/074873049701200603

73. Davis FC, Reppert SM. Development of mammalian circadian rhythms. In: Takahashi JS, Turek FW, Moore RY, editors. Circadian Clocks. Handbook of Behavioral Neurobiology. New York, NY: Kluwer Academic/Plenum Publishers (2001). p. 247-91.

74. Landgraf D, Achten C, Dallmann F, Oster H. Embryonic development and maternal regulation of murine circadian clock function. Chronobiol Int. (2015) 32:416-27. doi: 10.3109/07420528.2014.986576

75. Serón-Ferré M, Torres Farfán C, Forcelledo ML, Valenzuela GJ. The development of circadian rhythms in the fetus and neonate. Semin Perinatol. (2001) 25:363-70. doi: 10.1053/sper.2001.29037

76. Varcoe TJ, Boden MJ, Voultsios A, Salkeld MD, Rattanatray L, Kennaway DJ. Characterisation of the maternal response to chronic phase shifts during gestation in the rat: implications for fetal metabolic programming. PLoS ONE (2013) 8:e53800. doi: 10.1371/journal.pone.0053800

77. Weaver DR, Reppert SM. Periodic feeding of SCN-lesioned pregnant rats entrains the fetal biological clock. Dev Brain Res. (1989) 46:291-6. doi: 10.1016/0165-3806(89)90292-7

78. Bedont JL, Blackshaw S. Constructing the suprachiasmatic nucleus: a watchmaker's perspective on the central clockworks. Front Syst Neurosci (2015) 9:74. doi: 10.3389/fnsys.2015.00074

79. Moore RY, Smith RA. Postnatal development of a norepinephrine response to light in the rat pineal and salivary glands Neuropharmacology (1971) 10:315-23.

80. Speh JC, Moore RY. Retinohypothalamic tract development in the hamster and rat. Brain Res Dev Brain Res. (1993) 76:171-81. doi: 10.1016/0165-3806(93)90205-O

81. Zimmerman BL, Tso MO. Morphologic evidence of photoreceptor differentiation of pinealocytes in the neonatal rat. J Cell Biol. (1975) 66:60-75. doi: $10.1083 /$ jcb.66.1.60

82. Blackshaw S, Snyder SH. Developmental expression pattern of phototransduction components in mammalian pineal implies a light-sensing function. J Neurosci. (1997) 17:8074-82. doi: 10.1523/JNEUROSCI.17-21-08074.1997

83. Cajochen C, Frey S, Anders D, Späti J, Bues M, Pross A, et al. Evening exposure to a light-emitting diodes (LED)-backlit computer screen affects circadian physiology and cognitive performance. J Appl Physiol. (2011) 110:1432-8. doi: 10.1152/japplphysiol.00165.2011

84. Chang AM, Aeschbach D, Duffy JF, Czeisler CA. Evening use of light-emitting eReaders negatively affects sleep, circadian timing, and next-morning alertness. Proc Natl Acad Sci USA. (2015) 112:1232-7. doi: $10.1073 /$ pnas.1418490112

85. Chellappa SL, Steiner R, Oelhafen P, Lang D, Götz T, Krebs J, Cajochen C. Acute exposure to evening blue-enriched light impacts on human sleep. $J$ Sleep Res. (2013) 22:573-80. doi: 10.1111/jsr.12050

86. Cho CH, Lee HJ, Yoon HK, Kang SG, Bok KN, Jung KY, et al. Exposure to dim artificial light at night increases REM sleep and awakenings in humans. Chronobiol Int. (2016) 33:117-23. doi: 10.3109/07420528.2015. 1108980

87. Hatori M, Gronfier C, Van Gelder RN, Bernstein PS, Carreras J, Panda S, Marks F, et al. Global rise of potential health hazards caused by blue lightinduced circadian disruption in modern aging societies. NPJ Aging Mech Dis. (2017) 3:9. doi: 10.1038/s41514-017-0010-2

88. Stevens RG, Zhu Y. Electric light, particularly at night, disrupts human circadian rhythmicity: is that a problem? Philos Trans R Soc Lond B Biol Sci. (2015) 370:20140120. doi: 10.1098/rstb.2014.0120

89. Touitou Y, Reinberg A, Touitou D. Association between light at night, melatonin secretion, sleep deprivation, and the internal clock: health impacts and mechanisms of circadian disruption. Life Sci. (2017) 173:94-106. doi: 10.1016/j.lfs.2017.02.008

90. Zeitzer JM, Dijk DJ, Kronauer R, Brown E, Czeisler C. Sensitivity of the human circadian pacemaker to nocturnal light: melatonin phase resetting and suppression. J Physiol. (2000) 526:695-702. doi: $10.1111 /$ j.1469-7793.2000.00695.x
91. Duncan WC Jr. Circadian rhythms and the pharmacology of affective illness. Pharmacol Ther. (1996) 71:253-312.

92. Fonken LK, Nelson RJ. Effects of light exposure at night during development. Curr Opin Behav Sci. (2015) 7:33-9. doi: 10.1016/j.cobeha.2015.10.008

93. Knuttson A. Health disorders of shift workers. Occup Med. (2003) 53:103-8. doi: 10.1093/occmed/kqg048

94. Orr ST, James SA, Prince CB. Maternal prenatal depressive symptoms and spontaneous preterm births among African American women in Baltimore, Maryland. Am J Epidemiol. (2002) 156:797-802. doi: 10.1093/aje/kwf131

95. Salgado-Delgado RC, Pardo BF, Briones CE. La desincronización interna como promotora de enfermedad y problemas de conducta. Salud Mental (2009) 32:69-76.

96. Salgado-Delgado R, Tapia Osorio A, Saderi N, Escobar C. Disruption of circadian rhythms: a crucial factor in the etiology of depression. Depress Res Treat. (2011) 2011:839743. doi: 10.1155/2011/839743

97. Guide for the Care and Use of Laboratory Animals. Guide for the Care and Use of Laboratory Animals. 8th Edn. National Research Council (Author), Division on Earth and Life Studies (Author), Institute for Laboratory Animal Research. The National Academies Press (2011).

98. Castelhano-Carlos MJ, Baumans V. The impact of light, noise, cage cleaning and in-house transport on welfare and stress of laboratory rats. Lab Anim. (2009) 43:311-27. doi: 10.1258/la.2009.0080098

99. De Vera Mudry MC, Kronenberg S, Komatsu S, Aguirre GD. Blinded by the light; retinal phototoxicity in the context of safety studies. Toxicol Pathol. (2013) 41:813-25. doi: 10.1177/0192623312469308

100. Peirson SN, Brown LA, Pothecary CA, Benson LA, Fisk AS. Light and the laboratory mouse. J Neurosci Methods (2017) 300:26-36. doi: 10.1016/j.jneumeth.2017.04.007

101. Wren MA, Dauchy RT, Hanifin JP, Jablonski MR, Warfield B, Brainard GC, et al. Effect of different spectral transmittances through tinted animal cages on circadian metabolism and physiology in sprague-dawley rats. J Am Assoc Lab Anim Sci. (2014) 53:44-51

102. Jin X, Wy L, Zheng H., Mishima S. Retinal light damage: I. The influences of light intensity and exposure duration at moderate and low intensities of cyclic light. Yan Ke Xue Bao (1998) 14:215-9.

103. Semple-Rowland SL, Dawson WW. Cyclic light intensity threshold for retinal damage in albino rats raised under 6 lx. Exp Eye Res. (1987) 44:643-61.

104. Semple-Rowland SL, Dawson WW. Retinal cyclic light damage threshold for albino rats. Lab Anim Sci. (1987) 37:289-98.

105. Polosa A, Bessaklia H, Lachapelle P. Strain differences in light-induced retinopathy. PLoS ONE (2016) 11:e0158082. doi: 10.1371/journal.pone.0158082

106. Weisse I, Stötzer H, Knappen F, Walland A. The effect of clonidine on the pupil diameter and the retina in rats, assessed in relation to the intensity of light. Arzneim Forsch. (1971) 21:821-5.

107. Izumi Y, Ishikawa M, Benz AM, Izumi M, Zorumski CF, Thio LL. Acute vigabatrin retinotoxicity in albino rats depends on light but not GABA. Epilepsia (2004) 45:1043-8. doi: 10.1111/j.0013-9580.2004.01004.x

108. Boudard DL, Acar N, Bretillon L, Hicks D. Retinas of the diurnal rodent Arvicanthis ansorgei are highly resistant to experimentally induced stress and degeneration. Invest Ophthalmol Vis Sci. (2011) 52:8686-700. doi: 10.1167/iovs.11-8162

109. Refinetti R. Enhanced circadian photoresponsiveness after prolonged dark adaptation in seven species of diurnal and nocturnal rodents. Physiol Behav. (2007) 90:431-7. doi: 10.1016/j.physbeh.2006.10.004

110. Canal-Corretger MM, Vilaplana J, Cambras T, Díez-Noguera A. Functioning of the rat circadian system is modified by light applied in critical postnatal days. Am J Physiol Regul Integr Comp Physiol. (2001) 280:R1023-30. doi: 10.1152/ajpregu.2001.280.4.R1023

111. Cissé YM, Peng J, Nelson RJ. Dim light at night prior to adolescence increases adult anxiety-like behaviors. Chronobiol Int. (2016) 33:1473-80. doi: 10.1080/07420528.2016.1221418

112. Coleman G, Canal MM. Postnatal light effects on pup stress axis development are independent of maternal behavior. Front Neurosci. (2017) 11:46. doi: 10.3389/fnins.2017.00046

113. Prichard JR, Fahy JL, Obermeyer WH, Behan M, Benca RM. Sleep responses to light and dark are shaped by early experience. Behav Neurosci. (2004) 118:1262-73. doi: 10.1037/0735-7044.118.6.1262 
114. Biberman LM. Natural levels of illumination and irradiance. In: Biberman LM, Nudelman S, editors. Photoelectronic Imaging Devices. Optical Physics and Engineering. Boston, MA; New York, NY: Springer; Photoelectronic Imaging Devices@ Plenum Press (1971). p. 39-67.

115. Frank DW, Evans JA, Gorman MR. Time-dependent effects of dim light at night on re-entrainment and masking of hamster activity rhythms. J Biol Rhythms (2010) 25:103-12. doi: 10.1177/0748730409360890

116. Borniger JC, McHenry ZD, Abi Salloum BA, Nelson RJ. Exposure to dim light at night during early development increases adult anxiety-like responses. Physiol Behav. (2014) 133:99-106. doi: 10.1016/j.physbeh.2014.05.012

117. Cissé YM, Peng J, Nelson RJ. Effects of dim light at night on food intake and body mass in developing mice. Front Neurosci. (2017) 11:294. doi: 10.3389/fnins.2017.00294

118. Fonken LK, Workman JL, Walton JC, Weil ZM, Morris JS, Haim A, et al. Light at night increases body mass by shifting the time of food intake. Proc Natl Acad Sci USA. (2010) 107:18664-9. doi: 10.1073/pnas. 1008734107

119. Fonken LK, Aubrecht TG, Meléndez-Fernández OH, Weil ZM, Nelson RJ. Dim light at night disrupts molecular circadian rhythms and increases body weight. J Biol Rhythms (2013) 28:262-71. doi: 10.1177/0748730413493862

120. Fonken LK, Weil ZM, Nelson RJ. Mice exposed to dim light at night exaggerate inflammatory responses to lipopolysaccharide. Brain Behav Immun. (2013) 34:159-163. doi: 10.1016/j.bbi.2013.08.011

121. Bedrosian TA, Vaughn CA, Weil ZM, Nelson RJ. Behavior of laboratory mice is altered by light pollution within the housing environment. Anim Welfare (2013) 22:483-7. doi: 10.7120/09627286.22.4.483

122. Fonken LK, Nelson RJ. Dim light at night increases depressive-like responses in male C3H/HeNHsd mice. Behav Brain Res. (2013) 243:74-8. doi: 10.1016/j.bbr.2012.12.046

123. Fonken LK, Kitsmiller E, Smale L, Nelson RJ. Dim nighttime light impairs cognition and provokes depressive-like responses in a diurnal rodent. J Biol Rhythms (2012) 27:319-27. doi: 10.1177/0748730412448324

124. Fonken LK, Haim A, Nelson RJ. Dim light at night increases immune function in nile grass rats, a diurnal rodent. Chronobiol Int. (2012) 29:26-34. doi: 10.3109/07420528.2011.635831

125. Bedrosian TA, Fonken LK, Walton JC, Haim A, Nelson RJ. Dim light at night provokes depression-like behaviors and reduces CA1 dendritic spine density in female hamsters. Psychoneuroendocrinology (2011) 36:1062-9. doi: 10.1016/j.psyneuen.2011.01.004

126. Bedrosian TA, Fonken LK, Walton JC, Nelson RJ. Chronic exposure to dim light at night suppresses immune responses in Siberian hamsters. Biol Lett. (2011) 7:468-71. doi: 10.1098/rsbl.2010.1108

127. Stenvers D-J, van Dorp R, Foppen E, Mendoza J, Opperhuizen AL, Fliers E, et al. Dim light at night disturbs the daily sleep-wake cycle in the rat. Sci Rep. (2016) 6:35662. doi: 10.1038/srep35662

128. Brainard GC, Richardson BA, Petterborg LJ, Reiter RJ. The effect of different light intensities on pineal melatonin content. Brain Res. (1982) 233:75-81. doi: 10.1016/0006-8993(82)90931-3

129. Dauchy RT, Dauchy EM, Tirrell RP, Hill CR, Davidson LK, Greene MW, et al. Dark-phase light contamination disrupts circadian rhythms in plasma measures of endocrine physiology and metabolism in rats. Comp Med. (2010) 60:348-56.

130. Dauchy RT, Dupepe LM, Ooms TG, Dauchy EM, Hill CR, Mao L, et al. Eliminating animal facility light-at-night contamination and its effect on circadian regulation of rodent physiology, tumor growth, and metabolism: a challenge in the relocation of a cancer research laboratory. J Am Assoc Lab Anim Sci. (2011) 50:326-36.

131. Aston-Jones G, Card JP, Zhu Y, Gonzalez M, Haggerty E. The NE system as a target for hypocretin neurons: Implications for regulation of arousal. In: De Lecea L, Sutcliffe G, editors. Hypocretins as Integrators of Physiological Signals. Boston, MA: Kluwer/Springer (2005). p. 137-52.

132. Gotter AL, Webber AL, Coleman PJ, Renger JJ, Winrow CJ. International Union of basic and clinical pharmacology. LXXXVI. Orexin receptor function, nomenclature and pharmacology. Pharmacol Rev. (2012) 64:389420. doi: 10.1124/pr.111.005546

133. Mistlberger RE. Circadian regulation of sleep in mammals: role of the suprachiasmatic nucleus. Brain Res Brain Res Rev. (2005) 49:429-54. doi: 10.1016/j.brainresrev.2005.01.005
134. Yasenkov R, Deboer T. Interrelations and circadian changes of electroencephalogram frequencies under baseline conditions and constant sleep pressure in the rat. Neuroscience (2011) 180:212-221. doi: 10.1016/j.neuroscience.2011.01.063

135. Gould E, Woolley CS, Frankfurt M, McEwen BS. Gonadal steroids regulate dendritic spine density in hippocampal pyramidal cells in adulthood. $J$ Neurosci (1990) 10:1286-91. doi: 10.1523/JNEUROSCI.10-04-01286.1990

136. Poirier MF. Current trends in clinical psychiatric research. Presse Med. (1998) 27:2185-9.

137. Vadnie CA, McClung CA. Circadian rhythm disturbances in mood disorders: insights into the role of the suprachiasmatic nucleus. Neural Plast. (2017) 2017:1504507. doi: 10.1155/2017/1504507

138. Wehr TH, Rosenthal NE. Seasonality and affective illness. Am J Psychiatry (1989) 146:829-39. doi: 10.1176/ajp.146.7.829

139. Hacioglu G, Senturk A, Ince I, Alver A. Assessment of oxidative stress parameters of brain-derived neurotrophic factor heterozygous mice in acute stress model. Iran J Basic Med Sci. (2016) 19:388-93.

140. Scheiermann C, Kunisaki Y, Frenette PS. Circadian control of the immune system. Nat Rev Immunol. (2013) 13:190-8. doi: 10.1038/nri3386

141. Abolinis S, King EC, Lazarou L, Weldon L, Hughes L, Drescher P, et al. The comparative immunology of wild and laboratory mice, Mus musculus domesticus. Nat Commun. (2017) 8:14811. doi: 10.1038/ncomms14811

142. Takahashi JS, DeCoursey PJ, Bauman L, Menaker M. Spectral sensitivity of a novel photoreceptive system mediating entrainment of mammalian circadian rhythms. Nature (1984) 308:186-8. doi: 10.1038/308186a0

143. Brainard GC, Richardson BA, King TS, Reiter RJ. The influence of different light spectra on the suppression of pineal melatonin content in the Syrian hamster. Brain Res. (1984) 294:333-9. doi: 10.1016/0006-8993(84)91045-X

144. Sugden D. Melatonin biosynthesis in the mammalian pineal gland. Experientia (1989) 45:922-32. doi: 10.1007/BF01953049

145. Jardim-Perassi BV, Arbab AS, Ferreira LC, Borin TF, Varma NR, Iskander AS, et al. Effect of melatonin on tumor growth and angiogenesis in xenograft model of breast cancer. PLoS ONE (2014) 9:e85311. doi: 10.1371/journal.pone.0085311

146. Dauchy RT, Sauer LA, Blask DE, Vaughan GM. Light contamination during the dark phase in "photoperiodically controlled" animal rooms: effect on tumor growth and metabolism in rats. Lab Anim Sci. (1997) 47:511-8.

147. Dauchy RT, Blask DE, Sauer LA, Brainard GC, Krause JA. Dim light during darkness-stimulated tumor progression by enhancing tumor fatty acid uptake and metabolism. Cancer Lett. (1999) 144:131-6.

148. Gorman MR, Evans JA, Elliott JA. Potent circadian effects of dim illumination at night in hamsters. Chronobiol Int. (2006) 23:245-50. doi: 10.1080/07420520500521905

149. Jud C, Scmutz I, Hampp G, Oster H, Albrecht U. A guideline for analyzing circadian wheel-running behavior in rodents under different lighting conditions. Biol Proc. (2005) 7:101-16. doi: 10.1251/bpo109

150. Avery DH, Eder DN, Bolte MA, Hellekson CJ, Dunner DL, Vitiello $\mathrm{MV}$ et al. Dawn simulation and bright light in the treatment of SAD: a controlled study. Biol Psychiatry (2001) 50:205-16. doi: 10.1016/S0006-3223(01)01200-8

151. González MMC, Aston-Jones G. Circadian regulation of arousal: Role of the noradrenergic locus coeruleus system and light exposure. Sleep (2006) 29:1327-36. doi: 10.1093/sleep/29.10.1327

152. González MMC, Aston-Jones G. Light deprivation damages monoamine neurons and produces a depressive behavioral phenotype in rats. Proc Natl Acad Sci USA. (2008) 105:4898-903. doi: 10.1073/pnas.0703615105

153. Ramírez M, Arechaga G, Martínez JM, Prieto I, Ramírez-Expósito MJ, Sánchez B, et al. Environmental light-darkness conditions induce changes in brain and peripheral pyroglutamyl-peptidase I activity. Neurochem Res. (2001) 26:463-8. doi: 10.1023/A:1010996425408

154. Jameie SB, Mousavi M, Farhadi M, Mehraein F, Ababzadeh, Soleimani M, et al. Effects of total light deprivation on hippocampal neurogenesis and memory of adult rats: a sexual dimorphic study. Thrita (2016) 5:e36420. doi: 10.5812/thrita. 36420

155. Cambras T, Lopez L, Arias JL, Diez-Noguera A. Quantitative changes in neuronal and glial cells in the suprachiasmatic nucleus as a function of the lighting conditions during weaning. Brain Res Dev Brain Res. (2005) 157:27-33. doi: 10.1016/j.devbrainres.2005.02.014 
156. Marin MT, Araujo TT, Rezende M, Ribeiro-Barbosa ER. Behavioral alterations induced by absence of circadian light rhythm: effects of constant light or constant dark on depression-like behaviors and locomotor activity in rats. Biosci J. (2015) 31:1837-43. doi: 10.14393/BJ-v31n6a2015-28247

157. Tapia-Osorio A, Salgado-Delgado R, Angeles-Castellanos M, Escobar C. Disruption of circadian rhythms due to chronic constant light leads to depressive and anxiety-like behaviors in the rat. Behav Brain Res. (2013) 252:1-9. doi: 10.1016/j.bbr.2013.05.028

158. Coleman G, Gigg J, Canal MM. Postnatal light alters hypothalamic-pituitaryadrenal axis function and induces a depressive-like phenotype in adult mice. Eur J Neurosci. (2016) 44:2807-17. doi: 10.1111/ejn.13388

159. Zhang Y, Zhao Y, Pan F, Zhang P. EGb761 attenuates depressive-like behaviours induced by long-term light deprivation in C57BL/6J mice through inhibition of NF-кB-IL-6 signalling pathway. Cent Eur J Immunol. (2016) 41:350-7. doi: 10.5114/ceji.2016.63807

160. Lu CH, Wanga Y, Zhang YF. Light deprivation produces a sexual dimorphic effect on neural excitability and depression-like behavior in mice. Neurosc Lett. (2016) 633:69-76. doi: 10.1016/j.neulet.2016.09.013

161. Zhang YF, Li QQ, Qu J, Sun CM, Wang Y. Alterations of motor cortical microcircuit in a depressive-like mouse model produced by light deprivation. Neuroscience (2016) 341:79-94. doi: 10.1016/j.neuroscience.2016.11.026

162. Lu Ch, Li QQ, Li YY, Lin HZ, Qu J, Wang Y, et al. Light deprivation produces distinct morphological orchestrations on RGCs and cortical cells in a depressive-like YFP-H mouse model. Neurosci Lett. (2017) 659:60-8. doi: 10.1016/j.neulet.2017.08.073

163. Monje FJ, Cabatic M, Divisch I, Kim EJ, Herkner KR, Binder BR, et al. Constant darkness induces IL-6-dependent depression-like behavior through the NF-кB signaling pathway. J Neurosci. (2011) 31:9075-83. doi: 10.1523/JNEUROSCI.1537-11.2011

164. Ben-Hamo M, Larson TA, Duge LS, Sikkema C, Wilkinson ChW, de la Iglesia HO, et al. Circadian forced desynchrony of the master clock leads to phenotypic manifestation of depression in rats. eNeuro (2016) 3:6. doi: 10.1523/ENEURO.0237-16.2016

165. Li N, Karin M. Is NF-kappaB the sensor of oxidative stress? FASEB J. (1999) 13:1137-43.

166. Sayre LM, Smith MA, Perry G. Chemistry and biochemistry of oxidative stress in neurodegenerative disease. Curr Med Chem. (2001) 8:721-38. doi: 10.2174/0929867013372922

167. Wu A, Ying Z, Gomez-Pinilla F. Dietary omega-3 fatty acids normalize BDNF levels, reduce oxidative damage, and counteract learning disability after traumatic brain injury in rats. J Neurotrauma (2004) 21:1457-67. doi: 10.1089/neu.2004.21.1457

168. Numakawa T, Suzuki S, Kumamaru E, Adachi N, Richards M, Kunugi H. BDNF function and intracellular signaling in neurons. Histol Histopathol. (2010) 25:237-58. doi: 10.14670/HH-25.237

169. Burke TF, Advani T, Adachi M, Monteggia LM, Hensler JG. Sensitivity of hippocampal 5-HT1A receptors to mild stress in BDNF-deficient mice. Int J Neuropsychopharmacol. (2013) 16:631-45. doi: 10.1017/S1461145712000466

170. Tsuru J, Tanaka Y, Ishitobi Y, Maruyama Y, Inoue A, Kawano A, et al. Association of BDNF Val66Met polymorphism with HPA and SAM axis reactivity to psychological and physical stress. Neuropsychiatr Dis Treat. (2014) 10:2123-33. doi: 10.2147/NDT.S68629

171. Varela P, Escosteguy-Neto JC, Coelho CT, Mello LE, da Silveira DX, Santos-Junior JG. Chronic light deprivation inhibits appetitive associative learning induced by ethanol and its respective c-Fos and pCREB expression. Int J Neuropsychopharmacol. (2014) 17:1815-30. doi: $10.1017 /$ S1461145714000480

172. Karpova NN, Rantamäki T, Di Lieto A, Lindemann L, Hoener MC, Castrén E. Darkness reduces BDNF expression in the visual cortex and induces repressive chromatin remodeling at the BDNF gene in both hippocampus and visual cortex. Cell Mol Neurobiol. (2010) 30:1117-23. doi: 10.1007/s10571-010-9544-6

173. Martinowich K, Hattori D, Wu H, Fouse S, He F, Hu Y, Fan G, Sun YE. DNA methylation-related chromatin remodeling in activity-dependent BDNF gene regulation. Science (2003) 302:890-3. doi: 10.1126/science.1090842

174. Wilking M, Ndiaye M, Mukhtar H, Ahmad N. Circadian rhythm connections to oxidative stress: implications for human health. Antioxid Redox Signal. (2013) 19:192-208. doi: 10.1089/ars.2012.4889

175. Musiek ES, Lim MM, Yang G, Bauer AQ, Qi L, Lee Y, et al. Circadian clock proteins regulate neuronal redox homeostasis and neurodegeneration. J Clin Invest. (2013) 123:5389-400. doi: 10.1172/JCI70317

176. Qi G, Mi Y, Fan R, Li R, Wang Y, Li X, et al. Tea polyphenols ameliorate hydrogen peroxide and constant darkness-triggered oxidative stress via modulating the Keap1/Nrf2 transcriptional signaling pathway in HepG2 cells and mice liver. RSC Adv. (2017) 7:32198-208. doi: 10.1039/C7RA0 $5000 \mathrm{C}$

177. Benabid N, Mesfioui A, Ouichou A. Effects of photoperiod regimen on emotional behaviour in two tests for anxiolytic activity in Wistar rat. Brain Res Bull. (2008) 75:53-9. doi: 10.1016/j.brainresbull.2007.07.016

178. Fujinaka T, Kohmura E, Yuguchi T, Yoshimine T. The morphological and neurochemical effects of diffuse brain injury on the rat central noradrenergic system. Neurol Res. (2003) 25:35-41. doi: 10.1179/016164103101201094

179. Cryan JF, Slattery DA. Animal models of mood disorders: recent developments. Curr Opin Psychiatry (2007) 20:1-7. doi: 10.1097/YCO.0b013e3280117733

180. Kitayama I, Nakamura S, Takatoshi Y, Murase S, Nomura J, Kayahara T, et al. Degeneration of locus coeruleus axons in stress-induced depression model. Brain Res Bull. (1994) 35:573-80.

181. Amir S, Stewart J. Induction of Fos expression in the circadian system by unsignaled light is attenuated as a result of previous experience with signaled light: a role for Pavlovian conditioning. Neuroscience (1998) 83:657-61. doi: 10.1016/S0306-4522(97)00514-9

182. Dauchy RT, Wren MA, Dauchy EM, Hoffman AE, Hanifin JP, Warfield B, et al. The influence of red light exposure at night on circadian metabolism and physiology in Sprague-Dawley rats. J Am Assoc Lab Anim Sci. (2015) 54:40-50.

183. McCormack CE, Sontag CR. Entrainment by red light of running activity and ovulation rhythms of rats. Am J Physiol. (1980) 239:R450-3.

184. Ikeda M, Sagara M, Inoué S. Continuous exposure to dim illumination uncouples temporal patterns of sleep, body temperature, locomotion and drinking behavior in the rat. Neurosci Lett. (2000) 279:185-9. doi: 10.1016/S0304-3940(99)00943-X

185. Aguzzi J, Bullock NM, Tosini G. Spontaneous internal desynchronization of locomotor activity and body temperature rhythms from plasma melatonin rhythm in rats exposed to constant dim light. J Circadian Rhythms (2006) 4:4-6. doi: 10.1186/1740-3391-4-6

186. Fukuhara Ch, Aguzzi J., Bullock N., Tosini G. Effect of long-term exposure to constant dim light on the circadian system of rats. Neurosignals (2005) 14:117-25. doi: 10.1159/000086294

Conflict of Interest Statement: The author declares that the research was conducted in the absence of any commercial or financial relationships that could be construed as a potential conflict of interest.

Copyright (C) 2018 González. This is an open-access article distributed under the terms of the Creative Commons Attribution License (CC BY). The use, distribution or reproduction in other forums is permitted, provided the original author(s) and the copyright owner(s) are credited and that the original publication in this journal is cited, in accordance with accepted academic practice. No use, distribution or reproduction is permitted which does not comply with these terms. 